\title{
Synthesis, Structure, Crystallization and Mechanical Properties of Isodimorphic PBS-ran-PCL Copolyesters
}

\author{
Maryam Safari ${ }^{1}$, Itziar Otaegi ${ }^{1}$, Nora Aramburu ${ }^{1}$, Gonzalo Guerrica-Echevarria ${ }^{1}$, \\ Antxon Martínez de Ilarduya ${ }^{2} \mathbb{D}$, Haritz Sardon ${ }^{1}\left(\mathbb{D}\right.$ and Alejandro J. Müller ${ }^{1,3, *(\mathbb{C})}$
}

1 POLYMAT and Department of Polymers and Advanced Materials: Physics, Chemistry and Technology, Faculty of Chemistry, University of the Basque Country UPV /EHU, Paseo Manuel de Lardizabal, 3, 20018 Donostia-San Sebastián, Spain; maryam.safari@polymat.eu (M.S.); itziar.otaegi@ehu.eus (I.O.); nora.aramburu@ehu.eus (N.A.); gonzalo.gerrika@ehu.eus (G.G.-E.); haritz.sardon@ehu.eus (H.S.)

2 Departament d'Enginyeria Química, L'Escola Tècnica Superior d'Enginyeria Industrial de Barcelona (ETSEIB), Universitat Politècnica de Catalunya, Diagonal 647, 08028 Barcelona, Spain; antxon.martinez.de.ilarduia@upc.edu

3 IKERBASQUE, Basque Foundation for Science, Plaza Euskadi 5, 48009 Bilbao, Spain

* Correspondence: alejandrojesus.muller@ehu.es; Tel.: +34-943-018-191

check for

updates

Citation: Safari, M.; Otaegi, I.; Aramburu, N.; Guerrica-Echevarria, G.; de Ilarduya, A.M.; Sardon, H.; Müller, A.J. Synthesis, Structure, Crystallization and Mechanical Properties of Isodimorphic PBS-ran-PCL Copolyesters. Polymers 2021, 13, 2263. https://doi.org/ $10.3390 /$ polym 13142263

Academic Editors: Rafael Antonio Balart Gimeno, Vicente Compañ Moreno, Ana María Díez-Pascual, Angels Serra, Rebeca Hernandez Velasco and David Mecerreyes

Received: 22 June 2021

Accepted: 6 July 2021

Published: 9 July 2021

Publisher's Note: MDPI stays neutral with regard to jurisdictional claims in published maps and institutional affiliations.

Copyright: (c) 2021 by the authors. Licensee MDPI, Basel, Switzerland. This article is an open access article distributed under the terms and conditions of the Creative Commons Attribution (CC BY) license (https:// creativecommons.org/licenses/by/ $4.0 /)$.

\begin{abstract}
Isodimorphic behavior is determined by partial inclusion of comonomer segments within the crystalline structure and arises from the comparatively similar repeating chain units of the parental homopolymers. Isodimorphic random copolymers are able to crystallize irrespective of their composition and exhibit a pseudo-eutectic behavior when their melting point values are plotted as a function of comonomer content. At the pseudo-eutectic point or region, two crystalline phases can coexist. On the right-hand and the left-hand side of the pseudo-eutectic point or region, only one single crystalline phase can form which is very similar to the crystalline structures of the parent homopolymers. This article aims to study the synthesis method, structure, crystallization behavior and mechanical properties of isodimorphic random PBS-ran-PCL copolyesters. Moreover, this study provides a comprehensive analysis of our main recent results on PBS-ran-PCL random copolyesters with three different molecular weights. The results show that the comonomer composition and crystallization conditions are the major factors responsible for the crystalline morphology, crystallization kinetics and mechanical performance of isodimorphic random copolyesters. Our studies demonstrate that in the pseudo-eutectic region, where both crystalline phases can coexist, the crystallization conditions determine the crystalline phase or phases of the copolymer. The relationships between the comonomer composition and mechanical properties are also addressed in this work.
\end{abstract}

Keywords: isodimorphism; PBS-ran-PCL; random copolymers; crystallization

\section{Introduction}

Polymers constitute basic structural materials that participate in vital life processes due to their applications and demands in diverse areas of science and industry. However, the concern about serious environmental crises caused by fossil sources has driven the research of biodegradable and biobased polymers [1-5]. Aliphatic polyesters are developing as an important branch of biodegradable and biocompatible polymers for uses in many diverse fields including coatings, drug delivery processes, packaging, tissue engineering and many more. Each of these applications seeks materials with specific chemical, physical, mechanical and degradation properties [6-10].

Unfortunately, these kinds of biopolymers do not usually meet all the mechanical requirements needed for specific applications and they are also characterized by a high degree of crystallinity which limits their biodegradation rate. This problem is often addressed by copolymerizing two different types of monomers. Copolymerization makes it possible to have a better control over the structures than by blending homopolymers. 
Moreover, the composition can be varied over a wide range, and molecular weight can be controlled to achieve the desired properties in the final product [11-13].

Among biodegradable polyesters, Poly ( $\varepsilon$-caprolactone) (PCL) has been widely considered as a good candidate for biomedical and packaging uses. PCL is a soft biocompatible and biodegradable semi-crystalline polyester that has a low melting point (about $55-70{ }^{\circ} \mathrm{C}$ ) and a low glass transition temperature (around $-60^{\circ} \mathrm{C}$ ). However, the mechanical properties and biodegradability of the neat PCL do not meet some of the demands of biomedical fields such as bone tissue engineering $[14,15]$. Poly(butylene succinate) (PBS) has a higher melting point than PCL $\left(\sim 120^{\circ} \mathrm{C}\right)$, good flexibility, toughness, thermal and chemical resistance [16,17].

Random copolymerization is a common and beneficial method of combining the desired properties of two different homopolymers in a single copolymer in order to tailor their biodegradation rates by controlling the crystallinity degree. Moreover, copolymerization can restrict the degree of copolymer crystallization and enhance their physical properties to expand their applications and meet the biodegradable polymer demand. The magnitudes of properties such as crystallinity, flexibility, crystallization and melting temperatures and the glass transition temperature change, and even the directions of these changes can be selected depending on composition. In contrast with the blending of immiscible polymers, random copolymerization creates random covalent bonds between two parent comonomers, leading to full melt miscibility. Merging PCL properties such as softness, flexibility, biocompatibility with those of PBS, can result in a material that can be used in a wider range of applications. The chemical structures of PBS-ran-PCL random copolyesters are shown in Figure 1.<smiles>CCC(=O)CCCCCOC</smiles>

Figure 1. Chemical structure of PBS-ran-PCL copolyesters.

There are three main behaviors in which random copolymers can crystallize which strongly depend on the molecular weight, molar ratio and most importantly, the chemical structure of the repeating units of the copolymer.

(1) Total inclusion behavior: It happens when the two comonomeric units contain similar repeating units. The chains can co-crystallize regardless of the composition, the so-called isomorphic behavior. In this case, the two comonomers are miscible in the crystalline state, and thermal and structural properties generally show a linear dependence on composition [18].

(2) Inclusion-exclusion behavior: When the two homopolymers have similar repeating units, but they do not share any crystalline structure, an isodimorphic behavior in the random copolymers can result. This group of random copolymers shows crystallization over the whole composition range and a pseudo-eutectic behavior characterized by a dominant crystalline structure at each side of the pseudo-eutectic point or region. Moreover, the changes in the unit cell parameters of both crystal phases with composition evidence comonomer inclusion. Our group has recently studied isodimorphism in several random copolymer systems [19-29]. Isodimorphic crystallization has recently been found in different types of random copolymers such as poly (decamethylene succinate-ran-decamethylene fumarate), poly (butylene succinate-co-cis-butene succinate) and poly (hexamethylene carbonate)-co-poly (hexamethylene urethane) [30-35].

(3) Total exclusion behavior: When the repeating units of two homopolymers are dissimilar, the minor comonomer would be completely kept out from the crystalline structure of the main component. Therefore, the transition temperatures and enthalpies de- 
crease significantly with increasing comonomer content and the copolymer remains completely amorphous over a large range of copolymer compositions [19].

In this paper, biodegradable poly(butylene succinate-ran-caprolactone) [PBS-ran-PCL] copolyesters with a higher molecular weight than those produced in our earlier works were synthesized successfully. This paper also reviews the main results of our recent research on the synthesis, crystalline structure, crystalline morphology and crystallization kinetics of PBS-ran-PCL. In order to study the effect of comonomer incorporation on the mechanical properties of isodimorphic random copolymers, tensile and DMTA tests were also performed.

\section{Materials and Methods}

\subsection{Materials}

1,4-butanediol (BD), $\varepsilon$-caprolactone (CL), dimethyl succinate (DMS) and titanium tetraisopropoxide (TTP)—as the catalyst—were purchased from Aldrich and were used as received.

\subsection{Synthesis Routes of $B S_{x} C L_{y}$ Random Copolyesters}

The first series of copolyesters were successfully synthesized through enzyme-catalyzed ring-opening polymerization (ROP) of butylene succinate cyclic oligomers and $\varepsilon$-caprolactone using lipase B from Candida antarctica (CALB) as a catalyst. Copolyesters obtained by these copolymerizations are named as $\mathrm{LM}_{W}-\mathrm{BS}_{\mathrm{x}} \mathrm{CL}_{\mathrm{y}}$. Weight average molecular weights of these copolyesters were between $4 \mathrm{k}$ and $14 \mathrm{~kg} / \mathrm{mol}$ and $\mathrm{LM}_{\mathrm{W}}$ denote them as low molecular weight materials in comparison with other series prepared later. $\mathrm{LM}_{\mathrm{W}}-\mathrm{BS}_{\mathrm{x}} \mathrm{CL}_{\mathrm{y}}$ were studied in detail in one of our previous works (see ref. [36] for more details).

As the molecular weight of copolyesters produced by enzymatic ROP is strongly affected by polymerization conditions, such as the presence of small traces of water molecules and low reaction temperatures, the second series of copolyesters were synthesized by a metal-catalyzed melt-polymerization in the presence of titanium tetraisopropoxide (TTP) as the catalyst in order to increase the molecular weight $[37,38]$. In summary, the transesterification-ROP reactions of $\varepsilon$-caprolactone (CL), 1,4-butanediol (BD) and dimethyl succinate (DMS) were carried out at $160^{\circ} \mathrm{C}$ for $4 \mathrm{~h}$, and then the polymerizations were completed by polycondensation at reduced pressure and $190^{\circ} \mathrm{C}$ for $3 \mathrm{~h}$. We named this series of copolyesters $\mathrm{MM}_{\mathrm{W}}-\mathrm{BS}_{\mathrm{x}} \mathrm{CL}_{\mathrm{y}}$ (i.e., medium molecular weights series). These copolyesters were studied in detail in our previous research works (see refs. [37,38]). The weight-average molecular weights of $\mathrm{MMw}-\mathrm{BS}_{\mathrm{x}} \mathrm{CL}_{\mathrm{y}}$ copolyesters were between $17 \mathrm{k}-30 \mathrm{~kg} / \mathrm{mol}$. The $\mathrm{M}_{\mathrm{W}}$ of $\mathrm{MM}_{\mathrm{W}}-\mathrm{BS}_{\mathrm{x}} \mathrm{CL}_{\mathrm{y}}$ copolyesters were close to 4 times higher than those of the first series of copolyesters synthesized by enzymatic ROP copolymerization (named $\mathrm{LM}_{\mathrm{W}}-\mathrm{BS}_{\mathrm{x}} \mathrm{CL}_{\mathrm{y}}$ ).

In this work, the third series of PBS-ran-PCL copolymers were synthesized in order to obtain very high molecular weight copolyesters. Hence, by increasing the polycondensation time (to $6 \mathrm{~h}$ ) and the temperature (to $220^{\circ} \mathrm{C}$ ), we obtained high molecular weight copolyesters (named $\mathrm{HMw}-\mathrm{BS}_{\mathrm{x}} \mathrm{CL}_{\mathrm{y}}$ ) (see Table $\mathrm{S} 1$ ). The weight average molecular weights of the $\mathrm{HM}_{\mathrm{W}}-\mathrm{BS}_{\mathrm{x}} \mathrm{CL}_{\mathrm{y}}$ copolyesters are in the range of $40 \mathrm{k}-90 \mathrm{~kg} / \mathrm{mol}$ and are around 10 times higher than those of the first series of copolyesters synthesized by enzymatic ROP copolymerization $\left(\mathrm{LM}_{\mathrm{W}}-\mathrm{BS}_{\mathrm{x}} \mathrm{CL}_{\mathrm{y}}\right)$.

As a result, three series of PBS-ran-PCL random copolymers were synthesized successfully over a wide range of compositions by changing the polycondensation conditions so as to obtain different molecular weights. The copolyesters synthesized for this research work were abbreviated as: $\mathrm{zM}_{\mathrm{W}}-\mathrm{BS}_{\mathrm{x}} \mathrm{CL}_{\mathrm{y}}$. The molar ratio of each component, determined by ${ }^{1} \mathrm{H}-\mathrm{NMR}$, is subscripted ( $\mathrm{x}$ and $\mathrm{y}$ ) and $\mathrm{z}$ indicates the $\mathrm{M}_{\mathrm{W}}$ range of each series (low, medium and high), which was determined by gel permeation chromatography (GPC).

\subsection{Nuclear Magnetic Resonance (NMR)}

Both ${ }^{1} \mathrm{H}$ NMR and ${ }^{13} \mathrm{C}$ NMR spectra were recorded on a Bruker AMX-300 NMR instrument at 300.1 and $75.5 \mathrm{MHz}$, respectively. TMS was used as an internal reference and 
the copolyesters were dissolved in deuterated-chloroform $\left(\mathrm{CDCl}_{3}\right)$. The composition of the $\varepsilon$-caprolactone repeating unit in $\mathrm{BS}_{\mathrm{x}} \mathrm{CL}_{\mathrm{y}}$ was estimated by ${ }^{1} \mathrm{H}-\mathrm{NMR}$ spectra from proton resonance integrals of methylenes from succinate and $\varepsilon$-caprolactone units. Additionally, the CL-units and BS-units arrangement distributions of were calculated based on ${ }^{13} \mathrm{C} N M R$ signals of different methylene groups.

\subsection{Gel Permeation Chromatography (GPC)}

Molecular weight were determined by gel permeation chromatography (GPC) at $35^{\circ} \mathrm{C}$ in a Waters equipment, which was calibrated with monodisperse poly(methyl methacrylate) (PMMA) standards. Chromatography was performed with sodium trifluoroacetatehexafluoroisopropanol $(0.05 \mathrm{M})$ using a poly (styrene-co-divinylbenzene) column at a constant flow rate $(0.5 \mathrm{~mL} / \mathrm{min})$.

\subsection{Differential Scanning Calorimetry (DSC)}

A Perkin Elmer 8500 calorimeter was used to perform non-isothermal differential scanning calorimetry experiments. The calorimeter was connected to a refrigerated cooling system (Intracooler-2P) with a constant nitrogen flow rate $(20 \mathrm{~mL} / \mathrm{min})$ and calibrated with pure indium and tin standards. Approximately $5 \mathrm{mg}$ of sample were sealed in standard aluminum pans. The experiments were performed by the following protocol: Firstly, polymer samples were heated up from room temperature (around $25^{\circ} \mathrm{C}$ ) to $30^{\circ} \mathrm{C}$ above their melting point $\left(T_{m}+30^{\circ} \mathrm{C}\right)$ and held at this temperature for $3 \mathrm{~min}$ to erase any thermal history of the polymer. Secondly, samples were cooled down to $-60^{\circ} \mathrm{C}$, and finally, they were reheated up to $30^{\circ} \mathrm{C}$ above their $T_{m}$ at $10{ }^{\circ} \mathrm{C} / \mathrm{min}$. To define the glass transition temperature $\left(T_{g}\right)$, the thermal history of the samples was erased at $145^{\circ} \mathrm{C}$ for BS-rich samples and $90^{\circ} \mathrm{C}$ for CL-rich samples, by holding them at this temperature for $3 \mathrm{~min}$. Then, samples were cooled very fast (at about $160^{\circ} \mathrm{C} / \mathrm{min}$ ) to $-90^{\circ} \mathrm{C}$, by using the ballisticcooling option of DSC 8500 . Finally, samples were heated at a rate of $20^{\circ} \mathrm{C} / \mathrm{min}$. $T_{g}$ values were calculated from the heating scans at the midpoint of the heat capacity change.

\subsection{Tensile Test}

An Instron 5569 universal testing machine was used to perform the tensile tests. Dumbbell-shaped test specimens with dimensions according to ASTM D-638 (type V, thickness of 200 micrometers) were die-cut from films prepared by hot-pressing using a Collin P200E press. Young's modulus $(E)$, tensile strength $\left(\sigma_{b}\right)$ and ductility, measured as the elongation at break $\left(\varepsilon_{b}\right)$, were calculated from the load-displacement curves obtained at a crosshead speed of $10 \mathrm{~mm} / \mathrm{min}$. Five dumbbell-shaped samples were tested for each reported value.

\subsection{Dynamic Mechanical Thermal Analysis (DMTA)}

The phase behavior of copolymers was studied by DMTA (TA Q800 viscoelastometer). Samples were tested in the single cantilever bending mode at a constant heating rate and frequency $\left(4^{\circ} \mathrm{C} / \mathrm{min}, 1 \mathrm{~Hz}\right)$ from $-100{ }^{\circ} \mathrm{C}$ to $150{ }^{\circ} \mathrm{C}$.

\section{Results}

\subsection{Synthesis Results}

Table S1 shows molar composition, molecular weight and microstructural data for the synthesized copolyesters. NMR results prove/confirm the chemical structure of the random copolyesters. ${ }^{1} \mathrm{H}$ and ${ }^{13} \mathrm{C}$ NMR spectra of the $\mathrm{HM}_{\mathrm{W}}-\mathrm{BS}_{51} \mathrm{CL}_{49}$ composition are shown in Figure $\mathrm{S} 1$ and the spectra of the entire $\mathrm{HM}_{\mathrm{W}}-\mathrm{BS}_{\mathrm{x}} \mathrm{CL}_{\mathrm{y}}$ series are compared in Figure S2. The content of the $\varepsilon$-caprolactone and butylene succinate repeating units was estimated from methylene proton resonance integrals of $\mathrm{CH}_{2}$ (labeled as 1 in Figure S1a) and $\mathrm{CH}_{2}$ (labeled as 4 in Figure S1a). In addition, the sequence distributions of the BS and $\mathrm{CL}$ repeating units were calculated based on ${ }^{13} \mathrm{C}$ NMR signals of the methylene group $\mathrm{CH}_{2}$ labeled as b in Figure S1b. 
Figure 2a shows the molecular weight versus the CL-unit content of three series of synthesized PBS-ran-PCL copolyesters. The $T_{g}$ values of these 3 series of copolymers are plotted as a function of copolyester composition in Figure $2 \mathrm{~b}$. As expected for random copolymers, all copolymers showed a single glass transition temperature, which corresponds to a miscible amorphous phase. The $T_{g}$ values of the copolyesters are located between the $T_{g}$ values of the two parental homopolymers and are dependent on composition. Figure $2 \mathrm{~b}$ shows that the composition dependence follows the Gordon-Taylor fitting equation with the following Gordon-Taylor parameters: $k=0.23$ for $\mathrm{LM}_{\mathrm{W}}, k=0.62$ for $\mathrm{MM}_{\mathrm{W}}$ and $k=0.89$ for $\mathrm{HM}_{\mathrm{W}}-\mathrm{BS}_{\mathrm{x}} \mathrm{CL}_{\mathrm{y}}$ copolymers, respectively. These results are consistent with the properties of the random copolymers, as was previously demonstrated by NMR for all series of copolyesters.
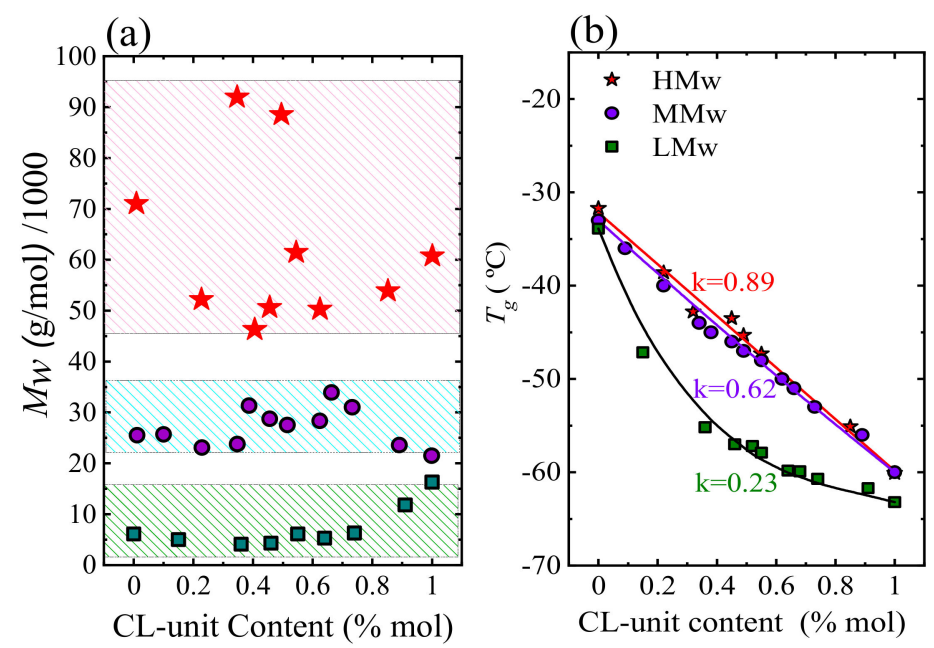

Figure 2. (a) $\mathrm{M}_{\mathrm{W}}$ of samples tested. (b) Glass transition temperature values versus composition for three series of copolyesters fitted with the Gordon-Taylor equation. k values are the Gordon-Taylor parameters.

\subsection{Non-Isothermal Melting-Crystallization Behavior}

The thermal properties of the synthesized copolyesters of different molecular weights were studied by non-isothermal DSC experiments. The standard non-isothermal behavior of neat $\mathrm{HM}_{\mathrm{W}}$-PBS and $\mathrm{HM}_{\mathrm{W}}$-PCL homopolymers, as well as $\mathrm{HM}_{\mathrm{W}}-\mathrm{BS}_{\mathrm{x}} \mathrm{CL}_{\mathrm{y}}$ copolymers at a cooling and heating rate of $10{ }^{\circ} \mathrm{C} / \mathrm{min}$ are shown in Figure 3. Table S2 shows the data extracted from DSC traces of $\mathrm{HM}_{\mathrm{W}}$-copolyesters.

As can be seen in Figure 3a, all copolyester compositions crystallized, and their $T_{\mathcal{c}}$ values were found to be a strong function of their composition. At the scale used in Figure 3, the crystallization peaks for four of the copolyesters were not very sharp. Therefore, a magnified scale of these DSC curves is plotted in Figure S3. When the parental comonomer units have very similar chemical structures, the copolymers can crystallize over the entire composition range.

Figure $4 \mathrm{a}-\mathrm{d}$ show plots of crystallization, melting and the corresponding enthalpy peaks for all 3 sets of copolyesters as a function of their composition. Figure $4 a, c$ show that both crystallization and melting temperatures of the copolymers are controlled by the composition. The effect of the molecular weight on both crystallization and melting temperature is very small (in some cases a small increase with molecular weight is appreciated). Firstly, it should be considered that all materials synthesized possess molecular weights higher than the critical value for the development of entanglements, and are therefore close to molecular weight values where these first order transitions are independent of molecular weights. Secondly, $T_{c}$ and $T_{m}$ values in isodimorphic random copolymers are regulated by the randomness of the distribution of the comonomer units and their arrangement through crystallization. In fact, the $T_{m}$ values are governed by the lamellar thickness achieved. 
However, both the crystallinity degree and the $T_{g}$ values of these isodimorphic random copolymers did change significantly with molecular weight, as these parameters depend on chain mobility and amorphous regions chain dynamics, respectively.

(a)

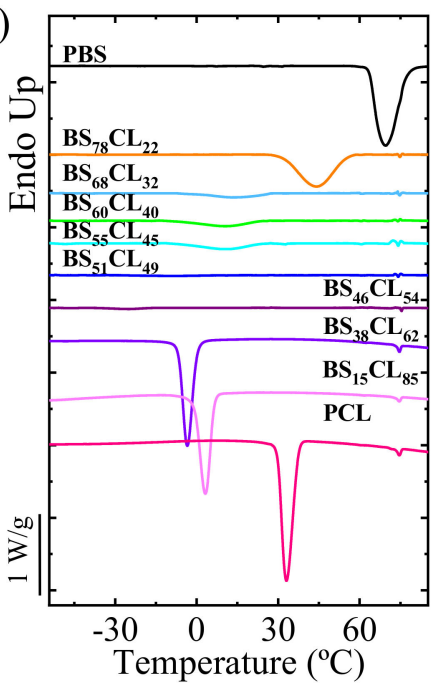

(b)

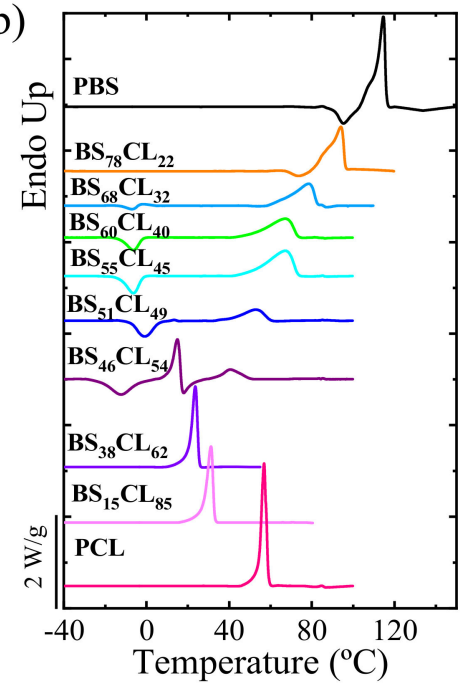

Figure 3. DSC cooling (a) and second heating (b) runs at a rate of $10{ }^{\circ} \mathrm{C} / \mathrm{min}$ for the $\mathrm{HM}_{\mathrm{W}}-\mathrm{BS}_{\mathrm{x}} \mathrm{CL}_{\mathrm{y}}$ copolyesters.
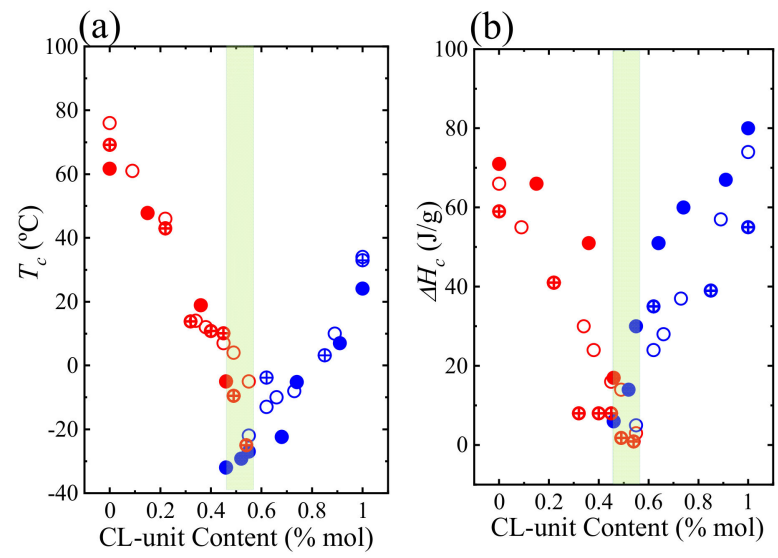

- PBS phase-LMw

- PCL phase-LMw

- PBS phase-MMw

- PCL phase-MMw

- PBS phase-HMw

$\oplus$ PCL phase-HMw

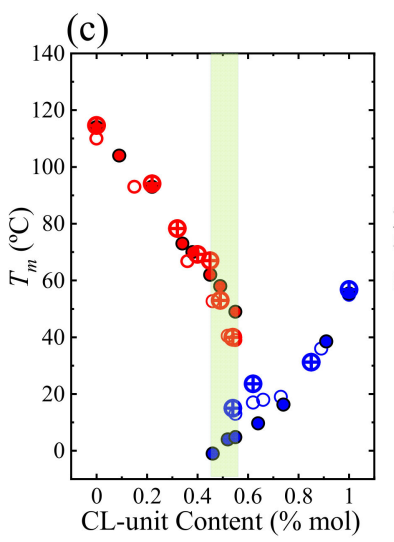

(d)

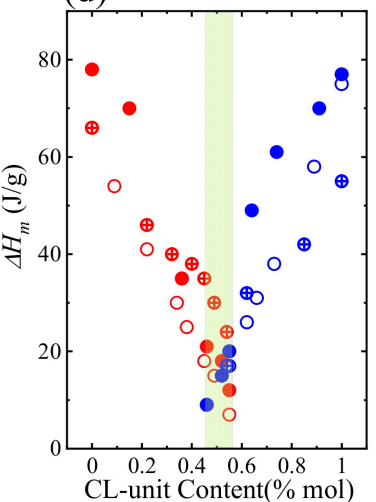

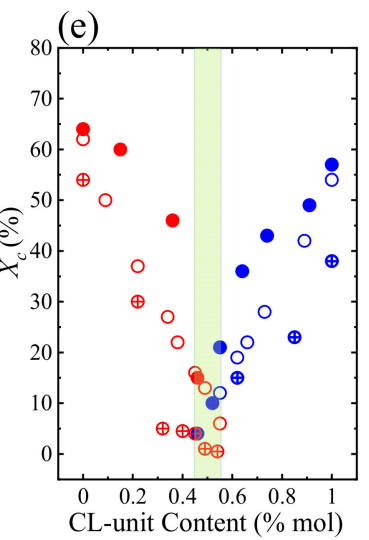

Figure 4. (a) Crystallization temperature $\left(T_{c}\right)$; (b) crystallization enthalpy $\left(\Delta H_{c}\right)$; (c) melting temperature $\left(T_{m}\right)$; (d) melting enthalpy $\left(\Delta H_{m}\right)$; and $(\mathbf{e})$ crystallization degree $\left(X_{c}\right)$ values of the three sets of copolyesters. The shaded composition range is the pseudo-eutectic region. 
Figure $4 \mathrm{~b}$,d shows the dependence of crystallization enthalpy $\left(\Delta H_{c}\right)$ and enthalpy of melting on the copolymer composition, respectively. The degree of crystallinity $\left(X_{c}\right)$ values of the copolyesters were calculated from the normalized melting enthalpies (normalized by their composition) and were plotted in Figure 4e. Both Figure 4d,e show the enthalpy of melting and the degree of crystallinity displayed a pseudo-eutectic-like behavior. The reduction in crystallinity of the phases as their composition approached the pseudo-eutectic point is caused by the comonomer exclusion during crystallization. As the comonomer content increases for both crystalline phases, comonomer exclusion decreases the length of crystallizable sequences that are included by limiting the number of the second comonomer units. Subsequently, increasing the amount of the second comonomer leads to a decrease in crystallization, because of the higher exclusion of the second comonomer from the crystal lattice.

In addition, Figure 4e shows the dependence of the degree of crystallinity on the molecular weight. The crystallinity degree also shows a pseudo-eutectic-like trend when plotted as a function of composition that arises from the comonomer exclusion during crystallization. The dramatic changes experience by the crystallinity with comonomer composition are ideal to tailor the biodegradation of these copolyesters, as biodegradation rate is inversily proportional to the crystallinity degree.

Furthermore, the lowest molecular weight copolyesters are able to show a higher degree of crystallinity than the other copolymers (Figure 4e), because of the faster diffusion of smaller molecules. Consequently, the higher molecular weight copolyesters, $\mathrm{HM}_{\mathrm{W}^{-}}$ $\mathrm{BS}_{\mathrm{x}} \mathrm{CL}_{\mathrm{y}}$, showed the lowest crystallinity degree, around $20-30 \%$ lower than the $\mathrm{MM}_{\mathrm{W}}$ copolyesters.

In isodimorphic copolymers, the major comonomer crystallizes within the unit cell of its homopolymer while it incorporates a small amount of the minor comonomer within the crystal lattice. The comonomer exclusion normally dominates when there is a competition between comonomer inclusion and comonomer exclusion. However, comonomer inclusion is essential for the formation of crystals over the whole composition range.

Figure 5 shows WAXS diffractogram of $\mathrm{MM}_{\mathrm{W}}$-copolymers. The characteristic reflections at $q=13.9,15.6$ and $16.1 \mathrm{~nm}^{-1}$ correspond to the PBS (020), (021) and (110) crystallographic planes and the reflections at $q=15.3$ and $17.4 \mathrm{~nm}^{-1}$ belong to the PCL (110) and (200) planes. Figure 5a shows that on the right side of the pseudo-eutectic point, PCL-like crystals are formed and, on the left side of this point, only PBS-like crystals are detected. For the composition at the eutectic point $\left(\mathrm{MM}_{\mathrm{W}}-\mathrm{BS}_{45} \mathrm{CL}_{55}\right)$, both crystalline phases were observed. As can be seen in Figure $5 \mathrm{~b}$, the $d$-spacings values of both PBS-rich and PCL-rich crystalline phases display important variations with comonomer content that are related to the changes in unit cell sizes and proves that there is comonomer inclusion.

The pseudo-eutectic sample, $\mathrm{MM}_{\mathrm{W}}-\mathrm{BS}_{45} \mathrm{CL}_{55}$, exhibits a very particular phase behavior, one or both phases can be formed depending on the crystallization conditions (via nonisothermal or isothermal crystallization) [37,38].

Figure 6 shows the phase diagram of $\mathrm{HM}_{\mathrm{W}}-\mathrm{BS}_{\mathrm{x}} \mathrm{CL}_{\mathrm{y}}$ copolyesters. This series of random high-molecular-weight copolymers display similar calorimetric properties to medium-molecular-weight $\mathrm{BS}_{\mathrm{x}} \mathrm{CL}_{\mathrm{y}}$ [37]. They show a single-phase melt and a single glass transition temperature and, upon cooling from the melt, the materials crystallize over the entire composition range as confirmed by $X$-ray diffraction studies. The copolymers display a pseudo-eutectic point, including two $T_{m}$ values at the $\mathrm{HM}_{\mathrm{W}}-\mathrm{BS}_{46} \mathrm{CL}_{54}$ composition, where two crystalline phases can form upon cooling from the melt, as proved earlier by WAXS and DSC. To each side of the pseudo-eutectic point, a single crystalline phase is formed; the left-hand side of the eutectic point is dominated by the PBS-rich phase and the right side, by the PCL-rich phase. It is interesting to note how one can obtain a separate control over $T_{g}$ and $T_{m}$ by regulating the composition of the copolymers. This affords unprecedented control to tailor the properties of these fascinating materials. 
(a)

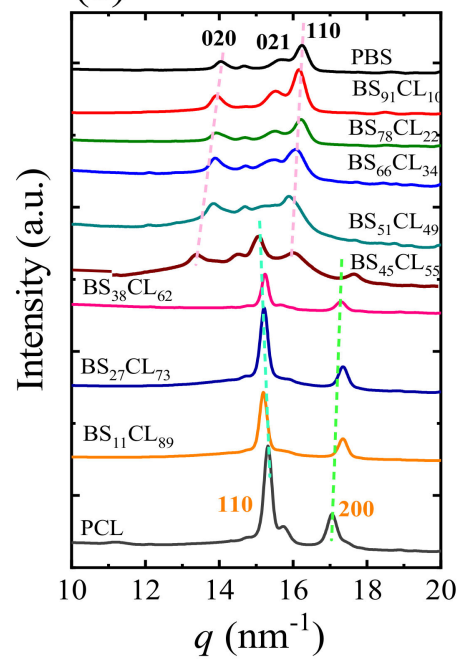

(b)

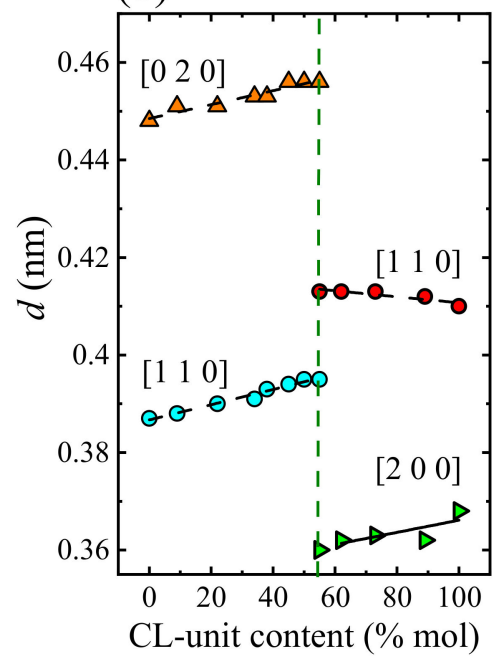

Figure 5. (a) WAXS diffraction patterns of $\mathrm{MM}_{\mathrm{W}}$-BSxCLy recorded at $-60{ }^{\circ} \mathrm{C}$ after cooling from the melt at a $10{ }^{\circ} \mathrm{C} / \mathrm{min}$ rate. (b) $d$-spacings calculated from the WAXS peaks shown in (a) versus composition. Reprinted with permission from ref. [37]. Copyright 2018 American Chemical Society.

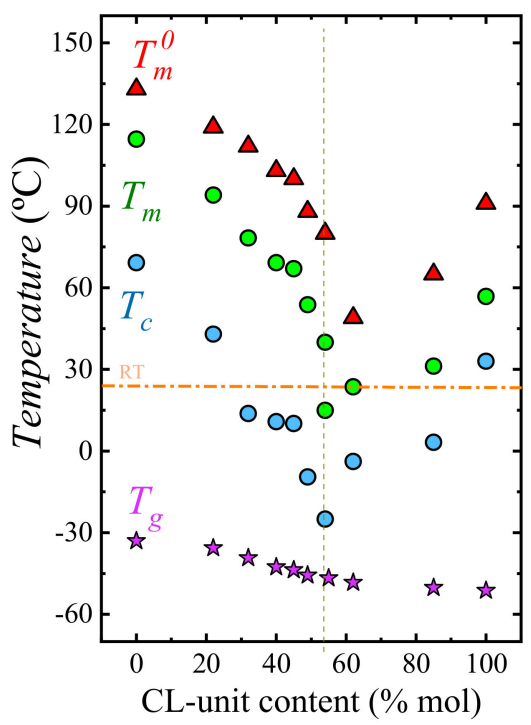

Figure 6. Phase diagram of the $\mathrm{HM}_{\mathrm{W}}-\mathrm{BS}_{\mathrm{x}} \mathrm{CL}_{\mathrm{y}}$ copolymers based on the non-isothermal crystallization, also showing equilibrium-melting temperatures $\left(T_{m}{ }^{0}\right)$ obtained by the Hoffman-Weeks analysis of the isothermal crystallization of samples. The short-dashed upright line specifies the pseudo-eutectic point. The dash-dotted horizontal line represents the room temperature.

\subsection{Controlling Single or Double Crystalline Phases at the Pseudo-Eutectic Point by} Non-Isothermal and Isothermal Crystallization

Of the $\mathrm{MM}_{\mathrm{W}}$ random copolyesters, only the $\mathrm{MM}_{\mathrm{W}}-\mathrm{BS}_{45} \mathrm{CL}_{55}$ composition shows a double crystalline morphology. This copolyester was isothermally crystallized from the melt at $20{ }^{\circ} \mathrm{C}$ for $2 \mathrm{~h}$ (see Figure $7 \mathrm{a}$ ). At this temperature, when cooling from a single molten phase, firstly the PBS-rich phase (blue lamellae in schematic diagrams) forms the spherulitic templates and the PCL chains are in the amorphous interlamellar regions. 


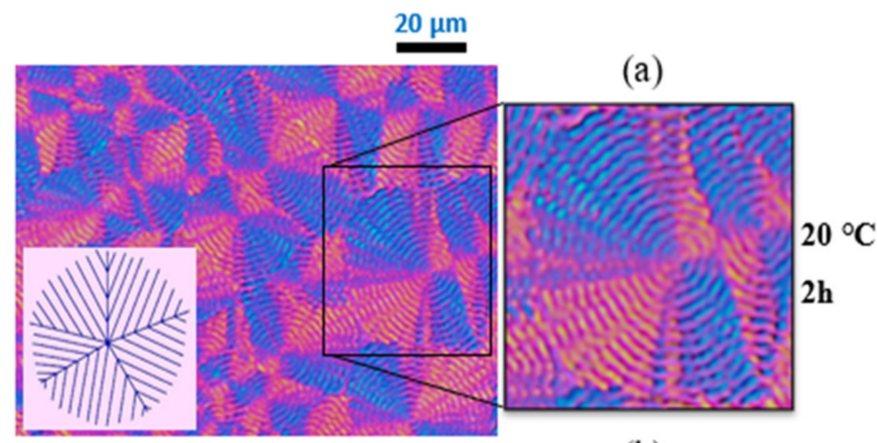

(b)
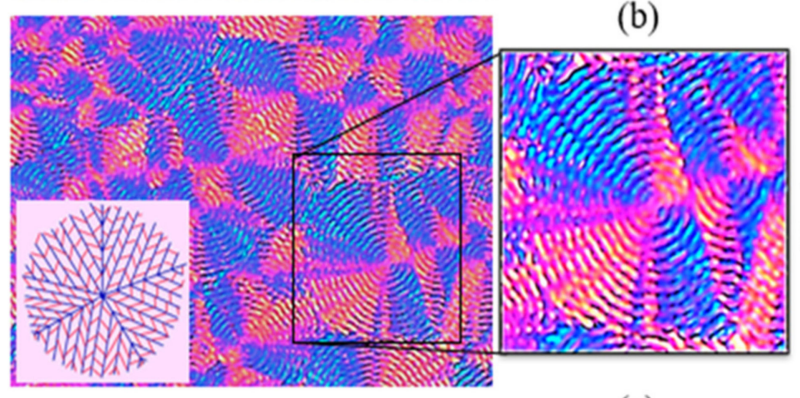

$-25^{\circ} \mathrm{C}$

$20 \min$

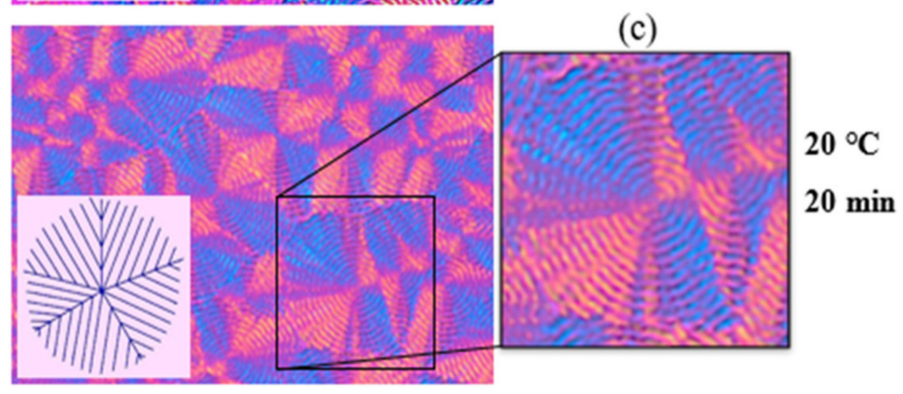

Figure 7. PLOM micrographs for the sample at the pseudo-eutectic point $\left(\mathrm{MM}_{\mathrm{W}}-\mathrm{BS}_{45} \mathrm{CL}_{55}\right)$. The schematic models are inserted at the bottom left of the PLOM images: (a) Crystallization of the sample by fast cooling from the melt to $20^{\circ} \mathrm{C}$ (holding for $2 \mathrm{~h}$ ). (b) Second step of crystallization by fast cooling from $20^{\circ} \mathrm{C}$ to $-25^{\circ} \mathrm{C}$ (holding for $20 \mathrm{~min}$ ). (c) Heating the sample to $20^{\circ} \mathrm{C}$ at a $10^{\circ} \mathrm{C} / \mathrm{min}$ rate. The blue lines in the schematic models display BS-rich lamellae, while the red lines represent CL-rich lamellae and the amorphous phase is represented by the pink background. Reprinted with permission from ref. [37]. Copyright 2018 American Chemical Society.

Quenching the sample from $20{ }^{\circ} \mathrm{C}$ to $-25^{\circ} \mathrm{C}$ results in the crystallization of the PCLrich phase (red inner lamellae in the sketch) within the intraspherulitic region of the PBSrich phase (see Figure $7 b$ ). Therefore, in Figure $7 b$, spherulite birefringence increases and the spherulitic structures look brighter, due to the double crystalline structure. Reheating the sample to $20^{\circ} \mathrm{C}$ causes the PCL-rich phase to melt from the intraspherulitic regions of the PBS phase while the PBS-rich phase spherulites remain in their crystalline form (Figure 7c).

\subsection{Controlling the Crystalline Phase over Non-Isothermal and Isothermal Crystallization for} Compositions at the Pseudo-Eutectic Point

Figure 8a shows cooling runs of the $\mathrm{MM}_{\mathrm{W}}-\mathrm{BS}_{45} \mathrm{CL}_{55}$ composition at the pseudoeutectic point at different cooling rates and Figure 8b shows subsequent heating scans at $20^{\circ} \mathrm{C} / \mathrm{min}$. The cooling rate has a clear effect on the PBS-rich and PCL-rich crystal phases at the pseudo-eutectic point. At a very low cooling rate $\left(1^{\circ} \mathrm{C} / \mathrm{min}\right)$, the PBS-rich phase has enough time to fully grow well-developed spherulites of the PBS-rich phase that hinder the crystallization of the PCL-rich phase due to confinement effects, as can be seen in PLOM observations in Figure 8c, where only PBS-rich crystals can be seen. 
(a)

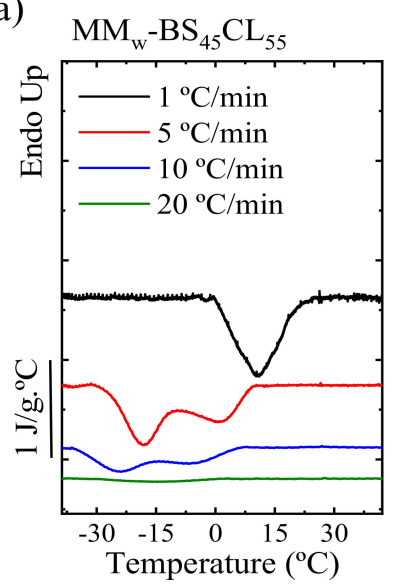

(c)

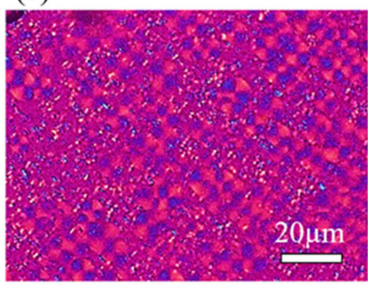

(f)

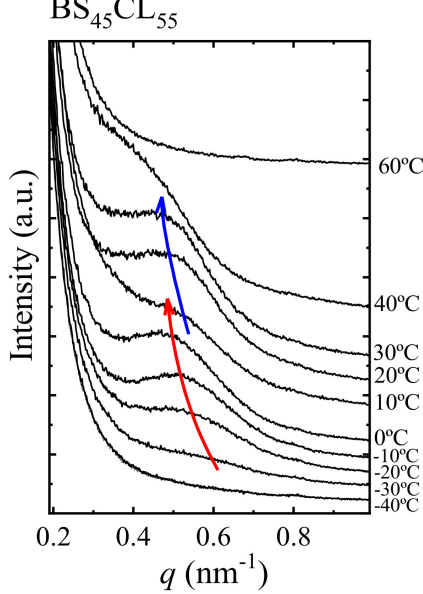

(g) (b)

(d)

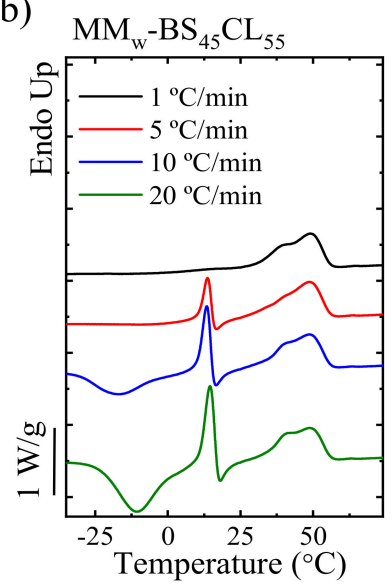

(e)
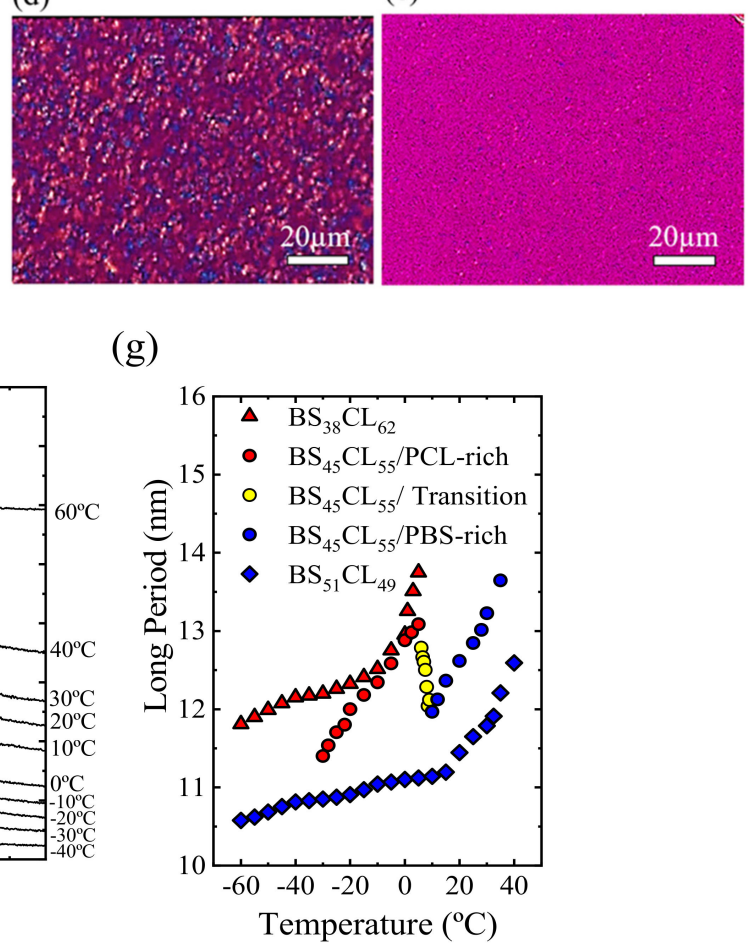

Figure 8. For $\mathrm{MM}_{\mathrm{W}}-\mathrm{BS}_{45} \mathrm{CL}_{55}$ sample (the sample at the pseudo-eutectic point): (a) cooling runs from the melt to $-60{ }^{\circ} \mathrm{C}$ at different cooling rates, (b) subsequent heating scans at $20^{\circ} \mathrm{C} / \mathrm{min}$. (c) PLOM micrographs taken after non-isothermal crystallization at different cooling rates: $5{ }^{\circ} \mathrm{C} / \mathrm{min}$, (d) $10^{\circ} \mathrm{C} / \mathrm{min}$ and $(\mathbf{e}) 20^{\circ} \mathrm{C} / \mathrm{min}$. (f) SAXS patterns registered during heating at $10^{\circ} \mathrm{C} / \mathrm{min}$. (g) Long period values extracted from the SAXS maxima during cooling for compositions close to and at the pseudo-eutectic point. Reprinted with permission from ref. [37]. Copyright 2018 American Chemical Society.

When increasing the cooling rate to 5 and $10^{\circ} \mathrm{C} / \mathrm{min}$, the DSC cooling scans show a bimodal crystallization exotherm. The DSC evidence clearly indicates that at these cooling rates both PBS and PCL-rich phases are able to crystallize and the PLOM micrograph in Figure $8 \mathrm{~d}$ shows crystals of both phases.

At higher cooling rates $\left(20^{\circ} \mathrm{C} / \mathrm{min}\right.$ and faster $)$, the PBS-rich phase cannot crystallize during the cooling process, allowing the PCL-rich phase to develop crystallinity as the PLOM micrograph in Figure 8e shows only very small spherulites of PCL-phase. Upon subsequent heating at $20^{\circ} \mathrm{C} / \mathrm{min}$ after non-isothermal crystallization, the PCL-rich phase undergoes cold crystallization for samples crystallized at rates above $5^{\circ} \mathrm{C} / \mathrm{min}$ and its crystallinity content increases. 
Figure $8 \mathrm{f}$ shows the SAXS patterns that were registered during the heating run for the sample at the pseudo-eutectic point $\left(\mathrm{BS}_{45} \mathrm{CL}_{55}\right.$ composition). The position of the single peak and the sharpness of the curves change with temperature. There is a remarkable change in the trend of the peak position above $0^{\circ} \mathrm{C}$, as soon as the PCL-rich crystals start to melt and the PBS-rich phase undergoes cold-crystallization.

In Figure $8 \mathrm{~g}$, the long period values (obtained from the SAXS maxima) are plotted as a function of temperature for the samples discussed above in Figure 8f. The composition at the pseudo-eutectic point shows a clear transition in the temperature region where the PCL-rich crystals melt and the PBS-rich phase undergoes cold crystallization.

In Figure 9a, DSC heating scans are recorded at $10^{\circ} \mathrm{C} / \mathrm{min}$ for a sample at the pseudoeutectic point $\left(\mathrm{MM}_{\mathrm{W}}-\mathrm{BS}_{45} \mathrm{CL}_{55}\right)$ after isothermal crystallization at the indicated $T_{c, \text { iso }}$ values from -14 to $30^{\circ} \mathrm{C}$. The $T_{m 2}$ corresponds to the melting of PCL-rich crystals and it appeared at $T_{c, \text { iso }}$ values lower than $-6^{\circ} \mathrm{C}$. The $T_{m 3}$ peak depends on the $T_{c, \text { iso }}$ and relates to the melting temperature of the PBS-rich crystals and it disappeared in the DSC heating curves where the $T_{c, i s o}$ is less than $-9{ }^{\circ} \mathrm{C}$.

(a)

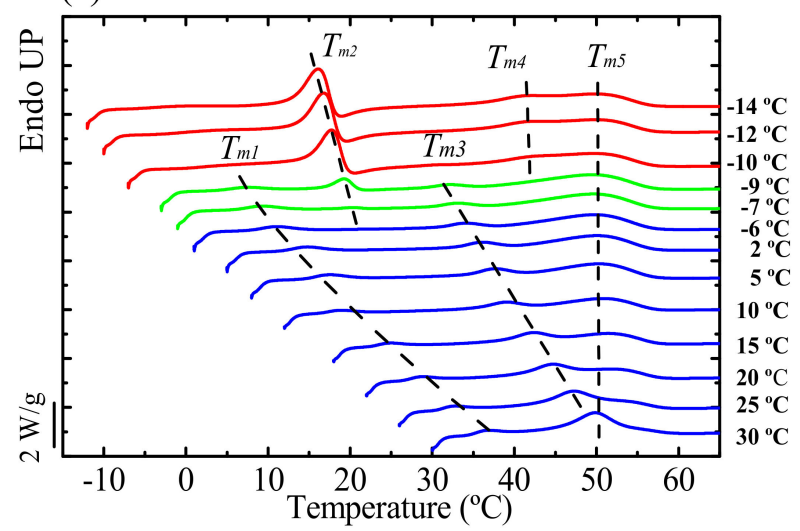

(b) $-12{ }^{\circ} \mathrm{C}$

(c) $-8{ }^{\circ} \mathrm{C}$

(d) $-4{ }^{\circ} \mathrm{C}$
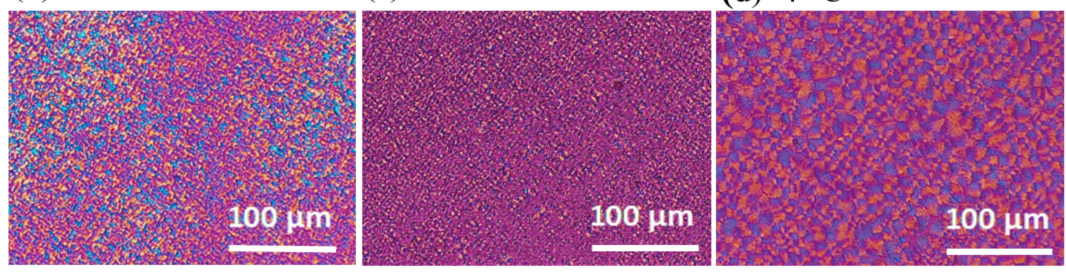

(e)

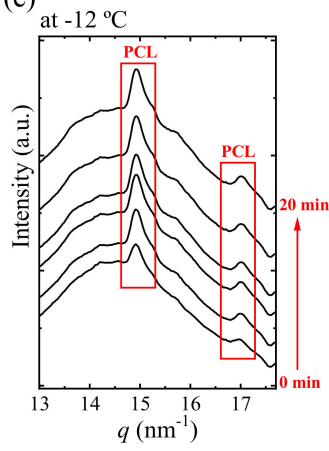

(f)

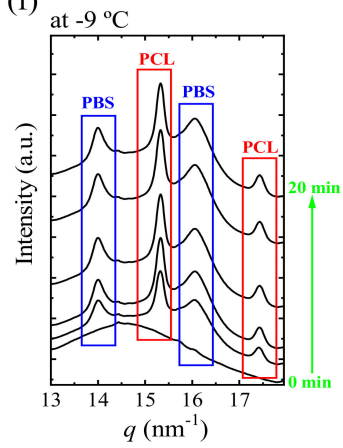

(g)

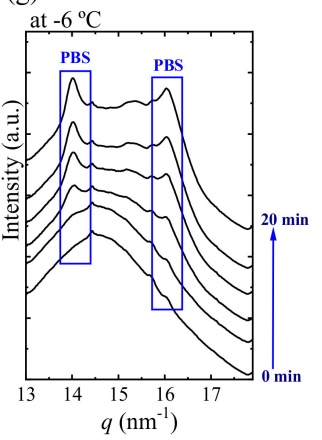

Figure 9. (a) DSC heating scans $\left(10^{\circ} \mathrm{C} / \mathrm{min}\right)$ after isothermal crystallization at indicated different temperatures for $\mathrm{MM}_{\mathrm{W}}-\mathrm{BS}_{45} \mathrm{CL}_{55}$-copolyester. PLOM micrographs taken after isothermal crystallization at $-12{ }^{\circ} \mathrm{C}(\mathrm{b}),-9{ }^{\circ} \mathrm{C}(\mathrm{c})$ and $-4{ }^{\circ} \mathrm{C}(\mathrm{d})$. WAXS patterns of the sample at the pseudo-eutectic point recorded during isothermal crystallization at $-12{ }^{\circ} \mathrm{C}(\mathbf{e}),-9^{\circ} \mathrm{C}(\mathbf{f})$ and $-6{ }^{\circ} \mathrm{C}(\mathrm{g})$. See ref. [38] for more details. 
Figure $9 \mathrm{~b}$ shows that only small spherulites of PCL crystals were formed at $T_{c, i s o}=-12{ }^{\circ} \mathrm{C}$. At $T_{c, i s o}=-8{ }^{\circ} \mathrm{C}$, where both PCL and PBS crystals can form, there are crystals of two sizes: PBS crystals with larger spherulites and PCL crystals with smaller spherulites (see Figure 9c). Figure $9 \mathrm{~d}$ shows only PBS spherulites that were formed at $T_{c, i s o}=-4{ }^{\circ} \mathrm{C}$.

Figure $9 \mathrm{e}-\mathrm{g}$ shows selected WAXS patterns for $\mathrm{MM}_{\mathrm{W}}-\mathrm{BS}_{45} \mathrm{CL}_{55}$ samples that were isothermally crystallized at $-12,-9$ and $-6{ }^{\circ} \mathrm{C}$. Figure $9 \mathrm{e}$ shows that at $-12{ }^{\circ} \mathrm{C}$ only the PCL-rich phase is able to crystalize, although at a higher temperature, $-6{ }^{\circ} \mathrm{C}$, only the PBS-rich phase crystallizes (see Figure 9g). On the other side, Figure $9 \mathrm{f}$ shows that at the intermediate crystallization temperature, $-9{ }^{\circ} \mathrm{C}$, both PBS-rich and PCL-rich phases are able to crystallize.

Bearing in mind the WAXS and DSC results shown in Figure 9, the DSC curves were plotted in color to indicate which phases can crystallize depending on the isothermal crystallization temperature. For the $T_{c, i s o}$ values at $-10{ }^{\circ} \mathrm{C}$ or lower, only the PCL-rich phase can form (see red curves in Figure $9 \mathrm{a}$ ). When the $T_{c, \text { iso }}$ values are between $-9{ }^{\circ} \mathrm{C}$ and $-7^{\circ} \mathrm{C}$, both the PCL-rich and the PBS-rich phases are able to crystallize (see green curves in Figure 9a). Finally, if the $T_{\mathcal{C}}$ temperatures are $-6^{\circ} \mathrm{C}$ and above, only the PBS-rich phase can form (see blue curves).

According to the isothermal and nonisothermal studies, the properties of this isodimorphic copolyester at the pseudo-eutectic point can be tailored by controlling the crystallization conditions.

\subsection{Isothermal Crystallization}

\subsubsection{Nucleation Kinetics Studied by PLOM}

Nucleation kinetics for $\mathrm{MM}_{\mathrm{W}}-\mathrm{BS}_{\mathrm{x}} \mathrm{CL}_{\mathrm{y}}$ copolyesters were studied by determining the nucleation density using PLOM. Figure 10 shows plots of nucleation density versus temperature taken at a constant nucleation time, $t=100 \mathrm{~s}$, for neat MMw-PBS and $\mathrm{MM}_{\mathrm{W}^{-}}$ PBS-rich copolymers and $t=10 \mathrm{~min}$ for neat $\mathrm{MM}_{\mathrm{W}}-\mathrm{PCL}$ and $\mathrm{MM}_{\mathrm{W}}$-PCL-rich copolymers. PLOM micrographs inserted in Figure 10 were taken after isothermal crystallization at a constant supercooling, $\Delta T=40^{\circ} \mathrm{C}$, for all samples.

PBS exhibits the lowest nucleation density of all samples and, hence, the largest spherulites, as can be seen in the inserted PLOM micrographs in Figure 10a. As the amount of CL comonomer increases in the PBS-rich copolymers, the nucleation density increases, as well as the supercooling needed for nucleation. PLOM micrographs inserted in Figure 10a shows that both spherulitic size and nucleation density are affected by copolymerization; increasing the amount of CL-unit content in the BS-rich copolymers leads to an increase in nucleation density and a reduction in spherulitic size.

On the other side, at an equal supercooling value, PCL shows a higher nucleation density than PBS (see Figure 10a,b). When a small amount of the BS comonomer is randomly incorporated in $\mathrm{BS}_{11} \mathrm{CL}_{89}$ samples, the nucleation density increases considerably. In obvious similarity (see micrographs inserted in Figure 10b), increasing the PBS content in the copolymer causes a rise in the nucleation density and, hence, a reduction in spherulitic size.

The nucleation rate $(I)$ values were obtained from the initial slope of the nuclei number versus time plots. As can be seen in Figure 11a, the nucleation rate is strongly influenced by the copolymer composition. The nucleation rate largely increases by adding a comonomer randomly along the chain to either PBS or PCL. As can be seen at the right of the pseudoeutectic point in Figure 11a, the PCL homopolymer shows faster nucleation than the PBS homopolymer, and the nucleation rate rises by adding PBS copolymer. 
(a)

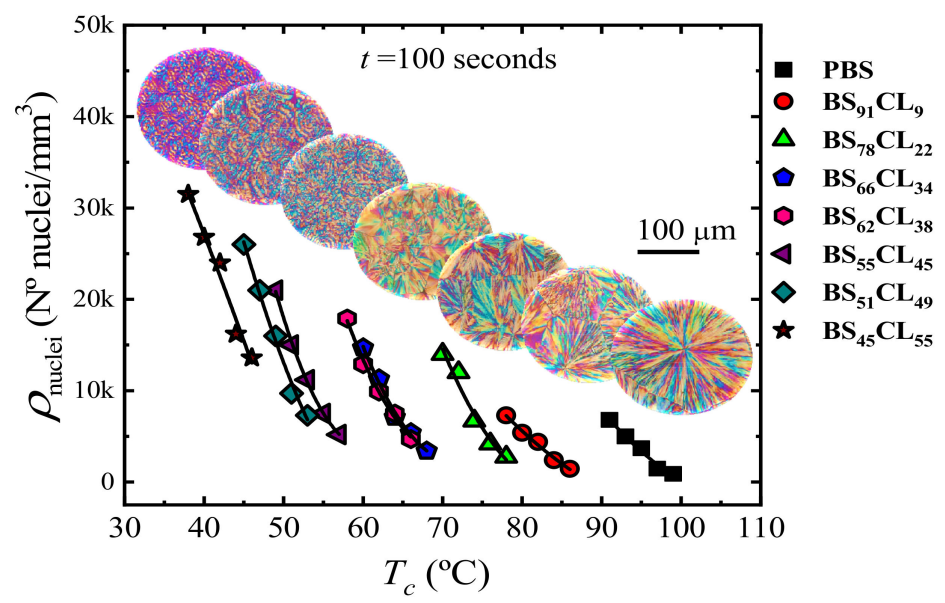

(b)

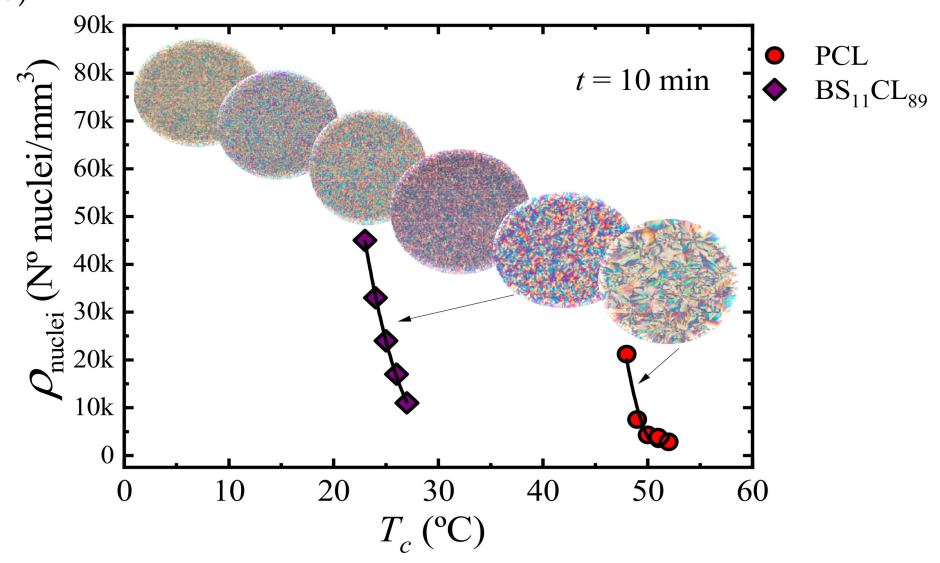

Figure 10. Nuclei density ( $\rho$ nuclei) as a function of crystallization temperature $\left(T_{c}\right)$ at $100 \mathrm{~s}$ for $\mathrm{MM}_{\mathrm{W}}$-PBS-rich (a) and at $10 \mathrm{~min}$ of isothermal crystallization for $\mathrm{MM}_{\mathrm{W}}$-PCL-rich (b) compositions. The inserted images are PLOM micrographs of each composition that crystallized isothermally at $\Delta T=40^{\circ} \mathrm{C}$. Data reported in ref. [38].
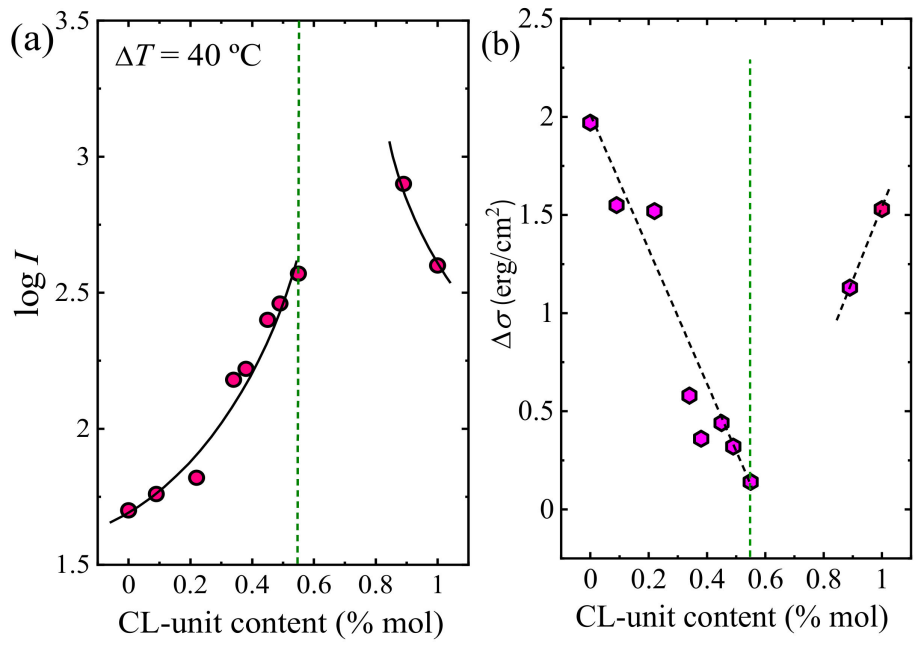

Figure 11. (a) $\log I$ (nucleation rate) as a function of copolymer composition taken at a constant supercooling of $\Delta T=40^{\circ} \mathrm{C}$ for MMw copolymers. (b) Interfacial free energy difference $(\Delta \sigma)$ values as a function of CL-unit composition. The dashed vertical lines indicate the pseudo-eutectic composition. Data reported in ref. [38]. 
Small values of the interfacial free energy difference $(\Delta \sigma)$ that were calculated from the Turnbull-Fisher plots, suggested a good nucleation efficiency as lower interfacial energy is necessary to form the crystal-substrate interface. As seen in Figure 11b, copolymerization of PBS with PCL facilitated the primary nucleation process, since the interfacial free energy difference decreases as the amount of $\mathrm{CL}$ in the copolymers increases.

At equivalent supercooling, $\Delta T=40^{\circ} \mathrm{C}, \mathrm{PCL}$ shows a larger nucleation density than PBS, since PCL has a smaller $\Delta \sigma$ value than PBS (see Figure 11b). On the right-hand side of the pseudo-eutectic point in Figure 11b, the $\Delta \sigma$ value decreases by the incorporation of $11 \%$ of $\mathrm{PBS}$ to the copolymer $\left(\mathrm{BS}_{11} \mathrm{CL}_{89}\right.$ copolymer) as a result of the increase in the nucleation capacity.

At a constant supercooling of $40{ }^{\circ} \mathrm{C}$, the experimental growth rate values $(G)$ decrease with comonomer incorporation for both BS-rich and CL-rich compositions. The reason could be the competition between inclusion and exclusion of repeating units within the crystal lattice, where the exclusion of the second comonomer dominates. Primary nucleation (Figure 11a) and secondary nucleation (Figure 12) show opposite trends when samples are crystallized at the same supercooling.

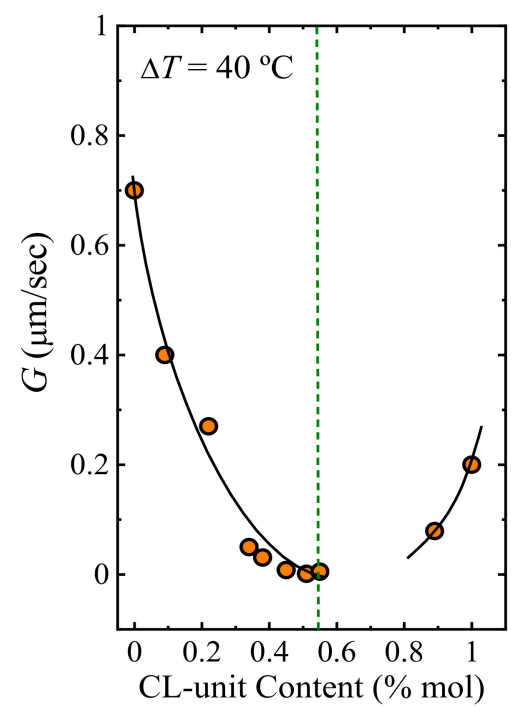

Figure 12. $G$ values versus CL-unit content at a constant super cooling of $40{ }^{\circ} \mathrm{C}$. The black lines are polynomial fits. Data reported in ref. [38].

\subsubsection{Studying Overall Crystallization Kinetics by DSC}

Isothermal crystallization was used to study overall crystallization kinetics (a kinetic process that encompasses nucleation and growth).

As can be seen in Figure 13a, the crystallization temperature tends to decrease as the comonomer content in the copolymer increases until the pseudo-eutectic point is reached at a constant crystallization rate of $1 \mathrm{~min}^{-1}$. This result is surely related to the plasticization effect caused by the molten PCL component. Moreover, the PCL exclusion from the PBS-rich crystal lattice may cause a greater reduction of the crystallization rate.

Figure $13 \mathrm{~b}$ shows the overall crystallization rate versus composition at constant supercooling $\left(45^{\circ} \mathrm{C}\right)$. For PBS-rich compositions, the overall crystallization rate decreases with the addition of $\mathrm{CL}$ units. A comparison with Figures 11a and 12 shows that the growth rate controls the overall crystallization of the PBS-rich compositions. Figure $13 \mathrm{~b}$ shows that at the right-hand side of the pseudo-eutectic point, the acceleration in the overall crystallization rate by the addition of BS comonomer can be explained by the increase in both primary and secondary nucleation rates. 

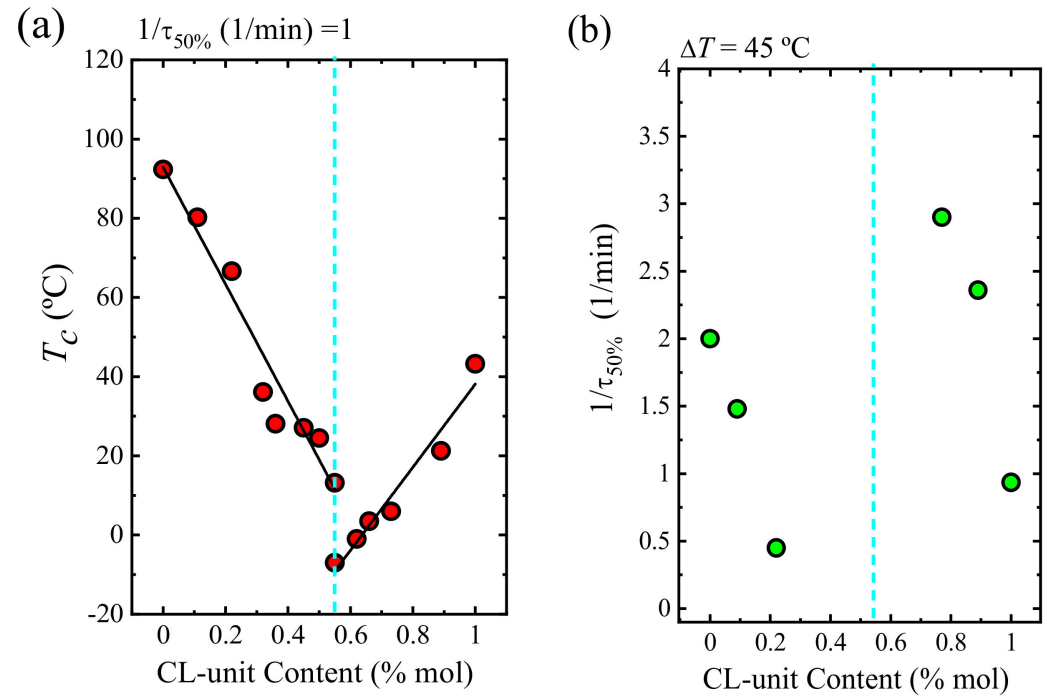

Figure 13. (a) $T_{\mathcal{C}}$ values as a function of CL-unit content at a constant rate $\left(1 / \tau_{50 \%}=11 / \mathrm{min}\right)$. (b) Inverse of half-crystallization time $\left(1 / \tau_{50} \%\right)$ as a function of the CL-unit content at a constant degree of supercooling $\left(\Delta T=45^{\circ} \mathrm{C}\right)$. Data reported in ref. [38].

The $K_{g}{ }^{G}$ values were obtained by applying the Lauritzen-Hoffman theory, and are proportional to the energy barrier for crystallization. Figure 14 plots both $K_{g}$ values as a function of the CL-unit molar content. The $K_{g}{ }^{G}$ values are obtained from PLOM studies and are related to the energy barrier for spherulitic growth, and $K_{g}{ }^{\tau}$ values are obtained from DSC studies and are related to the energy barrier for both primary nucleation and spherulitic growth. As expected $K_{g}{ }^{\tau}$ exhibit larger values (as they include both nucleation and growth) than $K_{g}{ }^{G}$ values which depend on growth only.

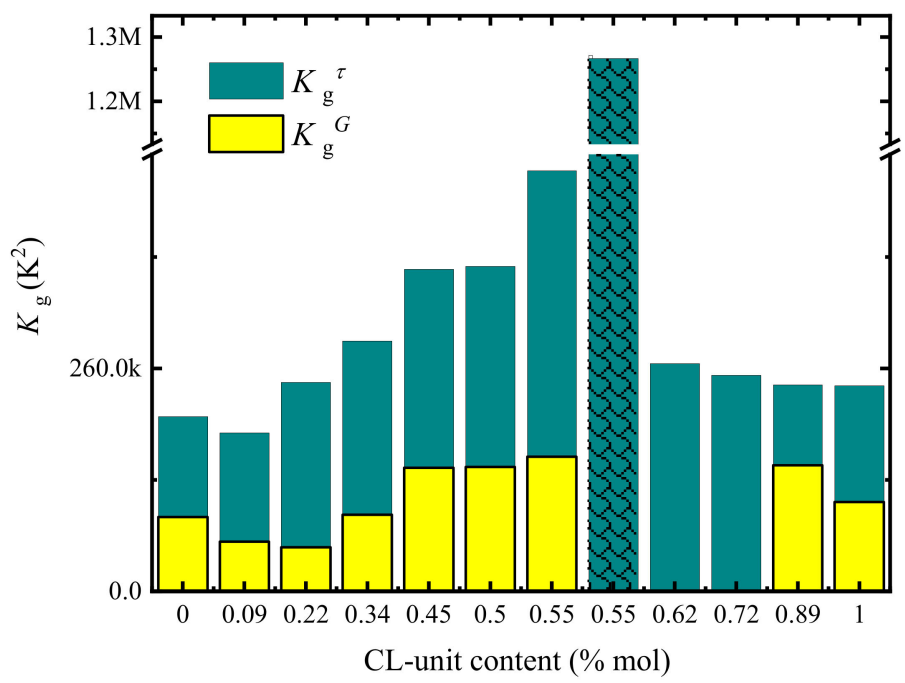

Figure 14. $K_{g}$ values versus copolymer composition calculated from PLOM experiments $\left(K_{g}{ }^{G}\right)$ and DSC experiments $\left(K_{g}{ }^{\tau}\right)$ for $\mathrm{MM}_{\mathrm{W}}-\mathrm{BS}_{\mathrm{x}} \mathrm{CL}_{\mathrm{y}}$ samples. This plot was reported in ref. [38].

On the PBS-rich side, $K_{g}{ }^{G}$ and $K_{g}{ }^{\tau}$ values increased with the CL-unit molar content, since the growth rate decreased and the nucleation rate increased with comonomer incorporation. On the PCL-rich side, where nucleation and growth rates show opposite trends, there is a counterbalance between nucleation and growth, which causes the $K_{g}{ }^{\tau}$ values to remain almost constant with composition. These results prove that there is a clear asymmetry depending on which side of the pseudo-eutectic region the composition is. 


\subsection{Mechanical Properties}

\subsubsection{Tensile Tests}

Representative stress-strain curves of the described copolyesters and their parental homopolymers are compared in Figure S4a,b for PBS-rich and PCL-rich phase copolyesters, respectively. Figure 15a-c show, respectively, the Young's modulus, stress at break and ductility values obtained from these curves plotted against the CL monomer content of the copolymers. As can be seen, the PBS homopolymer shows the highest elastic modulus and stress at break values, and the lowest elongation at break. The introduction of the CL comonomer caused a linear decrease in both $E$ and $\sigma$ as compared to the PBS homopolymer in the BS-rich composition range, along with an also linear increase of the elongation at break, with the $\mathrm{BS}_{46} \mathrm{CL}_{54}$ copolymer showing a two-fold increase with respect to PBS homopolymer. This is an expected result given the soft and flexible nature of PCL with respect to the PBS. In fact, a PBS homopolymer with a uniform sequence can exhibit a stronger inter-chain attraction due to its regular structure and the incorporation of flexible CL-units decreases the molecular chain regularity and improves the chain flexibility.
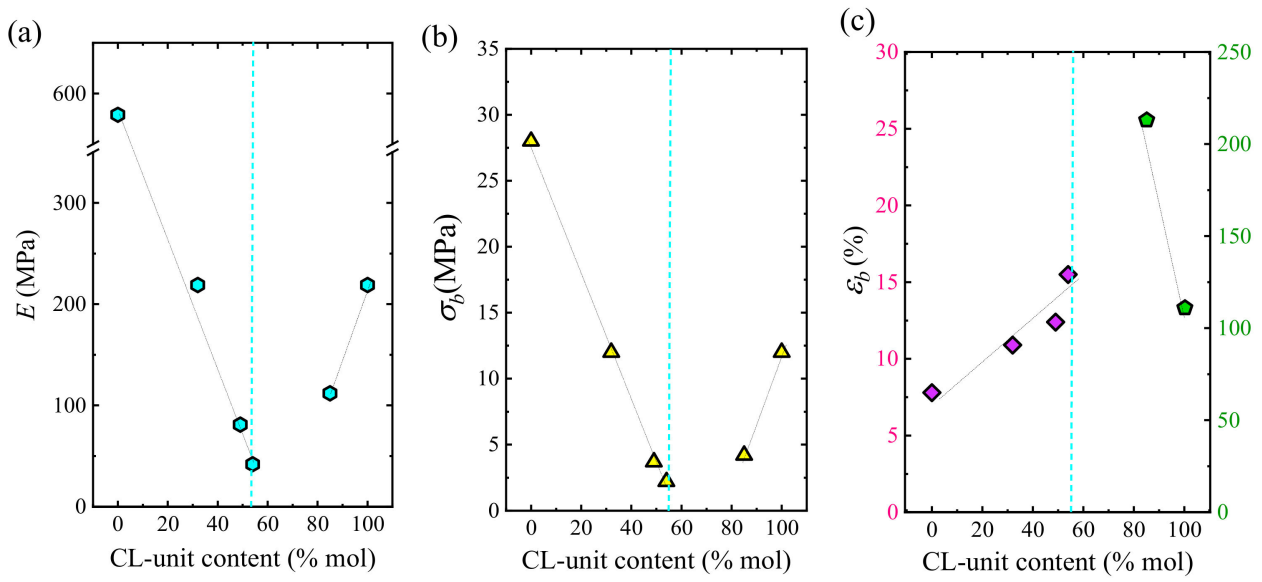

Figure 15. Mechanical properties of $\mathrm{HM}_{\mathrm{W}}-\mathrm{BS}_{\mathrm{x}} \mathrm{CL}_{\mathrm{y}}$ random copolyesters obtained from stress-strain curves. The elastic modulus $E(\mathbf{a})$, the stress at break $\sigma_{b}(\mathbf{b})$ and the elongation at break $\varepsilon_{b}(\mathbf{c})$ values are shown versus CL-unit content. The dotted blue line is the pseudo-eutectic composition.

However, it must be noticed that similar behavior can be observed at the other end of the composition range, i.e., in the CL-rich composition range. As can be seen in Figure 15a-c, the incorporation of a small amount of BS comonomer decreased elastic modulus and stress at break and enhanced ductility. The copolymer with $15 \%$ PBS showed a close-to-rubbery behavior with a high elongation at break and relatively low elastic modulus. Cao et al. [39] studied the tensile behavior of PBS-ran-PCL copolymers with average $M_{n}$ around 55,000 g/mol and found that the maximum elongation at break occurred for the $18 \%$ PBS composition, which is fairly close to the results obtained in this work.

When the behavior of these three mechanical properties is considered as a whole, a clear pseudo-eutectic trend can be observed when they are plotted as a function of the CL-unit content. Jin et al. [40] reported a comparable pseudo-eutectic behavior in those properties for isodimorphic poly (ethylene brassylate-ran- $\delta$-valerolactone) copolyesters. This pseudo-eutectic mechanical behavior is similar to that previously described for the degree of crystallinity, $X_{c}$, (see Table S2) and points to a non-surprising influence of this parameter on the mechanical properties.

It is worth noting that the degree of crystallinity is not the only factor determining the mechanical properties of the random copolymers. For instance, if we consider $\mathrm{BS}_{68} \mathrm{CL}_{32}$ $\left(X_{c}=5 \%\right)$ and $\mathrm{BS}_{15} \mathrm{CL}_{85}\left(X_{c}=23 \%\right)$, the copolymer containing BS-rich sequences presented higher $E$ and $\sigma_{b}$ with a poorer $\varepsilon_{b}$, despite the lower degree of crystallinity. As previously mentioned, the higher CL comonomer content in the latter with respect to the former 
must be considered, but it also agrees with a change in the major phase in these random copolyesters, as previously demonstrated by WAXS. Therefore, the mechanical behavior of isodimorphic random copolyesters are determined by the content of both crystalline and amorphous phases of the copolyesters.

\subsubsection{DMTA results}

Figure 16a shows the loss factor $(\tan \delta$ ) of hot-pressed samples as a function of temperature. The glass transition temperatures $\left(T_{g}\right)$ of copolyesters calculated from the maximum peak in $\tan \delta$ are summarized in Table 1, along with those obtained from the loss modulus ( $\left.E^{\prime \prime}\right)$ peak and DSC, for comparison purposes. As can be observed, the neat PBS sample showed the highest $T_{g}\left(-10^{\circ} \mathrm{C}\right)$; then, the $T_{g}$ value shifted to lower temperatures as the amount of CL comonomer was increased. The differences between the $T_{g} S$ measured by means of the $\tan \delta$ values and the $E^{\prime \prime}$ values are due to the fact that the $\tan \delta$ peak corresponds to the transition midpoint and the $E^{\prime \prime}$ peak corresponds to the onset transition region temperature [41].

(a)

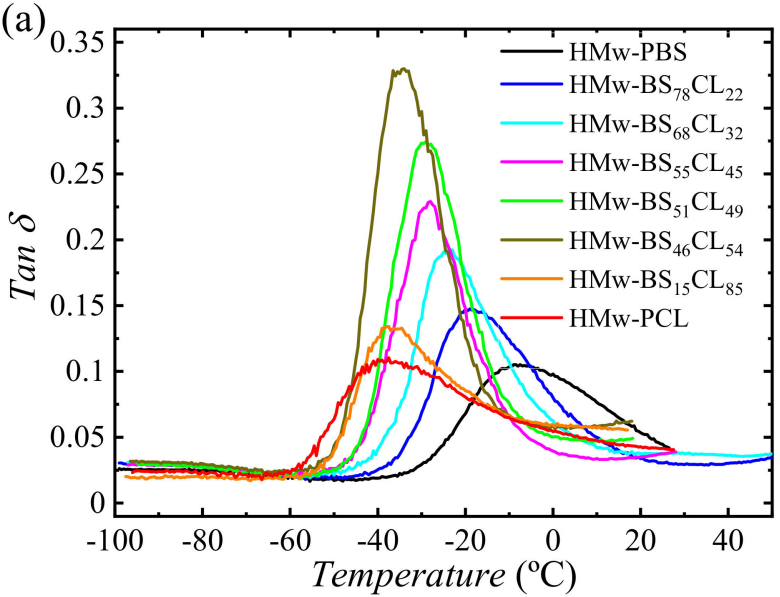

(b)

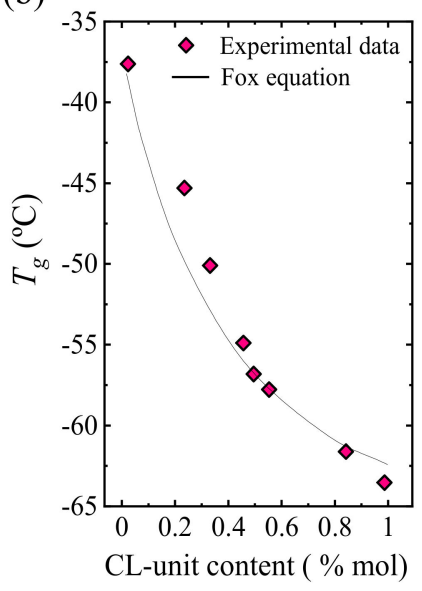

Figure 16. (a) Loss tangent $(\tan \delta)$ of the copolyesters as a function of temperature at a constant heating rate $\left(4{ }^{\circ} \mathrm{C} / \mathrm{min}\right)$ and frequency $(1 \mathrm{~Hz})$. (b) $\mathrm{T}_{\mathrm{g}}$ values of $\mathrm{HM}_{\mathrm{W}}-\mathrm{BS}_{\mathrm{x}} \mathrm{CL}_{\mathrm{y}}$ copolyesters (scattered data) as a function of in CL-units content (\% molar) and their fitting in the Fox equation (solid black line).

Table 1. $T_{g}$ values of $\mathrm{HM}_{\mathrm{W}}$ PBS-ran-PCL copolyesters extracted from the $\tan \delta$ peak and $E^{\prime \prime}$ of DMTA, and DSC measurements.

\begin{tabular}{cccc}
\hline Composition & $T_{g}\left({ }^{\circ} \mathrm{C}\right), \tan \delta$ & $T_{g}\left({ }^{\circ} \mathbf{C}\right), E^{\prime \prime}$ & $T_{g}\left({ }^{\circ} \mathbf{C}\right)$, DSC \\
\hline $\mathrm{HM}_{\mathrm{W}}$ PBS & -10.0 & -16.7 & -31.7 \\
$\mathrm{HM}_{\mathrm{W}}-\mathrm{BS}_{78} \mathrm{CL}_{22}$ & -18.1 & -24.0 & -38.6 \\
$\mathrm{HM}_{\mathrm{W}}-\mathrm{BS}_{68} \mathrm{CL}_{32}$ & -23.3 & -28.6 & -42.8 \\
$\mathrm{HM}_{\mathrm{W}}-\mathrm{BS}_{55} \mathrm{CL}_{45}$ & -28.5 & -33.4 & -43.5 \\
$\mathrm{HM}_{\mathrm{W}}-\mathrm{BS}_{51} \mathrm{CL}_{49}$ & -30.0 & -35.3 & -45.3 \\
$\mathrm{HM}_{\mathrm{W}}-\mathrm{BS}_{46} \mathrm{CL}_{54}$ & -33.8 & -40.9 & -47.3 \\
$\mathrm{HM}_{\mathrm{W}}-\mathrm{BS}_{15} \mathrm{CL}$ & -36.8 & -41.1 & -55.1 \\
$\mathrm{HM}_{\mathrm{W}}-\mathrm{PCL}$ & -37.5 & -43.3 & -60.1 \\
\hline
\end{tabular}

Typically, the $T_{g}$ values of the random copolymers are located between the $T_{g}$ values of two parental homopolymers and strongly rely on their composition [42]. To estimate the $T_{g}$ dependence on composition for a random copolymer, the Fox Equation (1) is usually applied [43]:

$$
1 / T_{g}=w_{1} / T_{g 1}+\left(1-w_{1}\right) / T_{g 2}
$$


where $T_{g 1}$ and $T_{g 2}$ are the glass transition temperatures of corresponding homopolymers 1 and $2\left(T_{g 1}<T_{g 2}\right)$ and $w_{1}$ and $w_{2}$ are the mass fraction of monomers 1 and 2, respectively. As can be seen in Figure 16b, the composition dependence was found to follow closely the Fox equation (Equation (1)).

As usual, the $T_{g}$ values obtained from DMTA (Figure $16 \mathrm{~b}$ and Table 1 ) were $20{ }^{\circ} \mathrm{C}$ higher than those measured by DSC (Figure $2 b$ and Table 1). DMTA applies a heating rate and simultaneously a mechanical deformation at a particular frequency; therefore, this factor increases the rate at which $T_{g}$ is being measured. The different method and conditions (heating rate) for the measurement in each experimental technique explain these differences.

The maximum intensity of the $\tan \delta$ peak can be applied for the quantitative analysis of the amorphous phase of the polymers [44]. As can be observed in Figure 16a, the intensity of the $\tan \delta$ peak increased at compositions close to the pseudo-eutectic one, pointing to a higher amount of the amorphous phase, in good agreement with previous DSC results. Furthermore, for PBS-ran-PCL copolymers, the $\tan \delta$ peak became narrower than in the case of the neat PBS and PCL, which may suggest that chain mobility is higher in the copolymers than in the homopolymers, probably due to the loss in chain regularity.

Figure 17a shows the storage modulus of all the copolymers and their corresponding homopolymers against temperature, while the loss modulus is plotted in Figure S5. As can be seen, $E^{\prime}$ showed a sharp decrease between -40 to $-20{ }^{\circ} \mathrm{C}$, depending on the composition. Figure $17 \mathrm{~b}$ shows the values of the storage modulus $E^{\prime}$ in the whole composition range at two specific temperatures: -80 and $10^{\circ} \mathrm{C}$. The storage modulus at the first one, which is below the glass transition temperature of the correspondent material in all cases, did not significantly change with composition, within an error of about $\pm 10 \%$. This is because at this temperature both amorphous and crystalline phases are in a rigid state and, consequently, there is no influence of the degree of crystallinity.

(a)

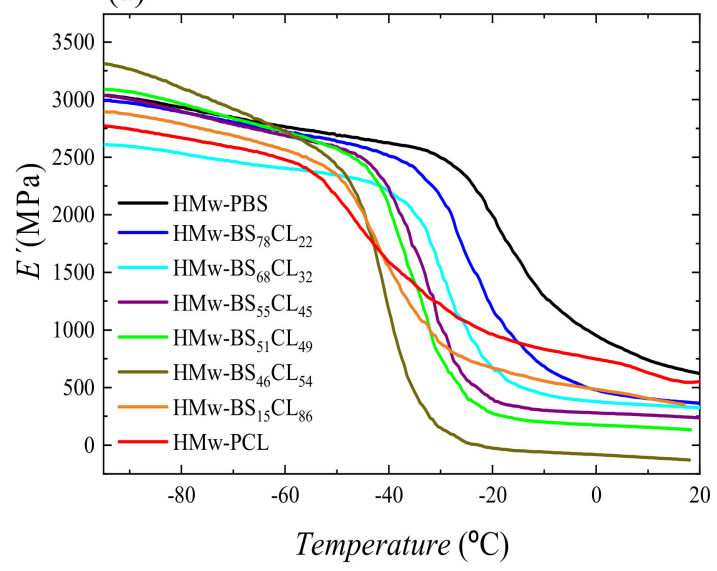

(b)

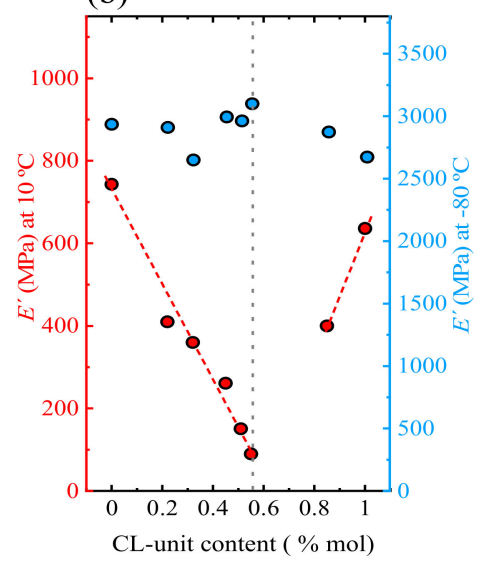

Figure 17. (a) Storage modulus of the $\mathrm{HM}_{\mathrm{W}}$ copolyesters as a function of temperature at $1 \mathrm{~Hz}$. (b) Storage modulus values at $-80^{\circ} \mathrm{C}$ and at $10^{\circ} \mathrm{C}$ versus CL-unit content. The dashed vertical line shows the position of the pseudo-eutectic composition.

On the contrary, Figure $17 \mathrm{~b}$ also shows that $E^{\prime}$ at $10^{\circ} \mathrm{C}$, which is above the $T_{g}$ of the correspondent material in all cases, showed a pseudo-eutectic behavior, similar to that observed both in $X_{c}$ and Young's modulus, pointing to the same relation between degree of crystallinity (isodimorphism) and stiffness of the material measured by the tensile test, which is also performed at temperatures above $T_{g}$.

\section{Conclusions}

Biodegradable PBS-ran-PCL copolyesters with three different molecular weight ranges (low, medium and high) were successfully synthesized by ring-opening polymerization 
and polycondensation-copolymerization. These random copolyesters could crystallize over the whole composition range and exhibited a pseudo-eutectic point, as evidenced by calorimetry.

The molecular weight variations did not affect the $T_{c}$ and $T_{m}$ values as they are regulated by the randomness of the distribution of the comonomer units. However, both the crystallinity degree and the $T_{g}$ values of these isodimorphic random copolymers did change significantly with molecular weight, as these parameters depend on chain mobility and long-range order cooperative chain movements.

The addition of comonomers to the major phase at both sides of the eutectic point causes an increase in the nucleation rate and nucleation density, but a decrease in the spherulitic growth rate. For PBS-rich copolymers, the overall crystallization rate was governed by the spherulitic growth rate. In contrast, for PCL-rich copolymers, the nucleation rate was the key main factor in the overall crystallization rate.

Only compositions at the pseudo-eutectic region or point can present double crystallization, and the formation of one or two phases is strongly dependent on the isothermal or non-isothermal crystallization conditions.

Comonomer incorporation at each side of the pseudo-eutectic point caused an increase in the elongation at break, and among the samples, the $\mathrm{BS}_{15} \mathrm{CL}_{85}$ composition displayed the highest elongation at break. In these copolymers, the loss modulus and tan $\delta$ curves exhibited a single $T_{g}$ peak that shifted from neat PBS to neat PCL by increasing the CL comonomer content. The composition dependence of the elastic modulus and stress at break values showed a similar pseudo-eutectic behavior at the same eutectic point displayed by crystallinity values, which indicated a significant correlation between the composition in isodimorphic copolymers and their mechanical properties. Storage modulus behaved differently below and above the glass transition temperature. Adding a comonomer randomly along the chain to either PCL or PBS did not affect the storage modulus at temperatures below $T_{g}$; however, because the degree of crystallinity is the predominant factor affecting the mechanical properties at temperatures above the glass transition, the storage modulus decreased when becoming closer to the pseudo-eutectic point.

The remarkable change in crystallinity and in first order thermal transitions with composition make these biodegradable random isodimorphic copolyester ideal materials to tailor their physical properties and biodegradation rates depending on the desired specific applications.

Supplementary Materials: The following are available online at https:/ /www.mdpi.com/article/10 $.3390 /$ polym13142263/s1, Figure S1: ${ }^{1} \mathrm{H}$ and ${ }^{13} \mathrm{C}$ NMR spectra of $\mathrm{HMw}-\mathrm{BS}_{51} \mathrm{CL}_{49}$ as representative of the $\mathrm{HM}_{\mathrm{W}}-\mathrm{BS}_{\mathrm{x}} \mathrm{CL}_{\mathrm{y}}$ copolyesters series, Figure $\mathrm{S} 2:{ }^{1} \mathrm{H}$ (a) and ${ }^{13} \mathrm{C}$ (b) NMR spectra comparison of all $\mathrm{HM}_{\mathrm{W}}-\mathrm{BS}_{\mathrm{x}} \mathrm{CL}_{\mathrm{y}}$ copolyesters series. Figure S3: Cooling DSC scans from the melt for those compositions that show a broad crystallization peak, Figure S4: Representative stress-strain curves of $\mathrm{HM}_{\mathrm{W}}-\mathrm{BS}_{\mathrm{x}} \mathrm{CL}_{\mathrm{y}}$ random copolyesters. Figure S5: Loss modulus as a function of temperature at a constant heating rate of $4{ }^{\circ} \mathrm{C} / \mathrm{min}$ and frequency of $1 \mathrm{~Hz}$ for $\mathrm{HM}_{\mathrm{W}}-\mathrm{BS}_{\mathrm{x}} \mathrm{CL}_{\mathrm{y}}$ copolyesters. Table S1: Synthesis results of the copolymerization of butylene succinate and $\varepsilon$-caprolactone. Table S2: Thermal characterization data of $\mathrm{HM}_{\mathrm{W}}-\mathrm{BS}_{\mathrm{x}} \mathrm{CL}_{\mathrm{y}}$ copolymer obtained from DSC. Table S3: Nucleation and growth constants obtained from isothermal crystallization kinetics of PBS homopolymer and PBS-rich phase compositions obtained by PLOM measurement. Table S4: Parameters obtained from fitting the DSC data presented in Figure 7a,b to the Lauritzen-Hoffman model.

Author Contributions: The general conceptualization of the work described here was performed by A.J.M., A.M.d.I. and H.S. designed the synthetic routes of the copolymers and their molecular characterization. The experiments were performed by M.S., I.O. and N.A. The general supervision of experimental measurements at the UPV/EHU labs was carried out by A.J.M., H.S., G.G.-E. and at UPC by A.M.d.I. and A.J.M. supervised calculations and fittings of experimental data. The paper was written by M.S. and A.J.M. and revised by all co-authors. All authors have read and agreed to the published version of the manuscript.

Funding: This research received the financial support from the BIODEST project. This project has received funding from the European Union's Horizon 2020 research and innovation programme 
under the Marie Skłodowska-Curie grant agreement No 778092. We also acknowledge funding from MINECO through grant MAT2017-83014-C2-1-P, and from the Basque Government through grant IT1309-19. This research was funded by ALBA synchrotron facility through granted proposal 2018082953.

Institutional Review Board Statement: Not applicable.

Informed Consent Statement: Not applicable.

Data Availability Statement: Data sharing not available.

Conflicts of Interest: The authors declare no conflict of interest.

\section{References}

1. Lendlein, A.; Sisson, A. Handbook of Biodegradable Polymers: Isolation, Synthesis, Characterization and Applications; Wiley-VCH: Weinheim, Germany, 2011.

2. Yu, L.; Dean, K.; Li, L. Polymer blends and composites from renewable resources. Prog. Polym. Sci. 2006, 31, 576-602. [CrossRef]

3. Gandini, M.N.B.; Belgacem, M.N. Monomers, Polymers and Composites from Renewable Resources; Elsevier: Amsterdam, The Netherlands, 2008.

4. Leja, K.; Lewandowicz, G. Polymer biodegradation and biodegradable polymers-a review. Polym. J. Environ. Stud. 2010, 19, 255-266.

5. Nair, L.S.; Laurencin, C.T. Biodegradable polymers as biomaterials. Prog. Polym. Sci. 2007, 32, 762-798. [CrossRef]

6. Zheng, Y.; Pan, P. Crystallization of biodegradable and biobased polyesters: Polymorphic crystallization, cocrystallization, and structure-property relationship. Prog. Polym. Sci. 2020, 109, 101291. [CrossRef]

7. Vert, M.; Li, S.M.; Spenlehauer, G.; Guérin, P. Bioresorbability and biocompatibility of aliphatic polyesters. J. Mater. Sci. Mater. Med. 1992, 3, 432-446. [CrossRef]

8. Chiulan, I.; Frone, A.N.; Brandabur, C.; Panaitescu, D.M. Recent advances in 3D printing of aliphatic polyesters. Bioengineering 2018, 5, 2. [CrossRef]

9. Siracusa, V.; Rocculi, P.; Romani, S.; Dalla Rosa, M. Biodegradable polymers for food packaging: A review. Trends Food Sci. Technol. 2008, 19, 634-643. [CrossRef]

10. Pillai, O.; Panchagnula, R. Polymers in drug delivery. Curr. Opin. Chem. Biol. 2001, 5, 447-451. [CrossRef]

11. Montaudo, G.; Rizzarelli, P. Synthesis and enzymatic degradation of aliphatic copolyesters. Polym. Degrad. Stab. 2000, 70, 305-314. [CrossRef]

12. Fields, R.D.; Rodriguez, F.; Finn, R.K. Microbial degradation of polyesters: Polycaprolactone degraded by P. pullulans. J. Appl. Polym. Sci. 1974, 18, 3571-3579. [CrossRef]

13. Zheng, Y.; Yanful, E.K.; Bassi, A.S. A review of plastic waste biodegradation. Crit. Rev. Biotechnol. 2005, 25, 243-250. [CrossRef] [PubMed]

14. Abedalwafa, M.; Wang, F.; Wang, L.; Li, C. Biodegradable poly-epsilon-caprolactone (PCL) for tissue engineering applications: A review. Rev. Adv. Mater. Sci. 2013, 34, 123-140.

15. Mohamed, R.M.; Yusoh, K. A review on the recent research of polycaprolactone (PCL). Adv. Mat. Res. 2016, 1134, 249-255. [CrossRef]

16. Sisti, L.; Totaro, G.; Marchese, P. PBS makes its entrance into the family of biobased plastics. In Biodegradable and Biobased Polymers for Environmental and Biomedical Applications; John Wiley \& Sons: Hobocan, NJ, USA, 2016; pp. 225-273.

17. Kanemura, C.; Nakashima, S.; Hotta, A. Mechanical properties and chemical structures of biodegradable poly (butylene-succinate) for material reprocessing. Polym. Degrad. Stab. 2012, 97, 972-980. [CrossRef]

18. Natta, G.; Corradini, P.; Sianesi, D.; Morero, D. Isomorphism phenomena in macromolecules. J. Poly. Sci. 1961, 51, 527-539. [CrossRef]

19. Pérez-Camargo, R.A.; Arandia, I.; Safari, M.; Cavallo, D.; Lotti, N.; Soccio, M.; Müller, A.J. Crystallization of isodimorphic aliphatic random copolyesters: Pseudo-eutectic behavior and double-crystalline materials. Eur. Polym. J. 2018, 101, $233-247$. [CrossRef]

20. Arandia, I.; Mugica, A.; Zubitur, M.; Arbe, A.; Liu, G.; Wang, D.; Mincheva, R.; Dubois, P.; Müller, A.J. How composition determines the properties of isodimorphic poly(butylene succinate-ran-butylene azelate) random biobased copolymers: From single to double crystalline random copolymers. Macromolecules 2015, 48, 43-57. [CrossRef]

21. Arandia, I.; Mugica, A.; Zubitur, M.; Iturrospe, A.; Arbe, A.; Liu, G.; Wang, D.; Mincheva, R.; Dubois, P.; Müller, A.J. Application of SSA Thermal fractionation and X-Ray diffraction to elucidate comonomer inclusion or exclusion from the crystalline phases in poly(butylene succinate-ran-butylene azelate) random copolymers. J. Poly. Sci. B Poly. Phy. 2016, 54, 2346-2358. [CrossRef]

22. Arandia, I.; Mugica, A.; Zubitur, M.; Mincheva, R.; Dubois, P.; Müller, A.J.; Alegria, A. The complex amorphous phase in poly(butylene succinate-ran-butylene azelate) isodimorphic copolyesters. Macromolecules 2017, 50, 1569-1578. [CrossRef]

23. Arandia, I.; Zaldua, N.; Maiz, J.; Pérez-Camargo, R.A.; Mugica, A.; Zubitur, M.; Mincheva, R.; Dubois, P.; Müller, A.J. Tailoring the isothermal crystallization kinetics of isodimorphic poly(butylene succinate-ran-butylene azelate) random copolymers by changing composition. Polymer 2019, 183, 121863. [CrossRef] 
24. Arandia, I.; Meabe, L.; Aranburu, N.; Sardon, H.; Mecerreyes, D.; Müller, A.J. Influence of chemical structures on isodimorphic behavior of three different copolycarbonate random copolymer series. Macromolecules 2020, 53, 669-681. [CrossRef]

25. Pérez-Camargo, R.A.; Fernández-d'Arlas, B.; Cavallo, D.; Debuissy, T.; Pollet, E.; Avérous, L.; Müller, A.J. Tailoring the Structure, Morphology, and Crystallization of Isodimorphic Poly(butylene succinate-ran-butylene adipate) Random Copolymers by Changing Composition and Thermal History. Macromolecules 2017, 50, 597-608. [CrossRef]

26. Basterretxea, A.; Gabirondo, E.; Flores, I.; Etxeberria, A.; Gonzalez, A.; Müller, A.J.; Mecerreyes, D.; Coulembier, O.; Sardon, H. Isomorphic polyoxyalkylene copolyethers obtained by copolymerization of aliphatic diols. Macromolecules 2019, 52, 3506-3515. [CrossRef]

27. Safari, M.; Leon Boigues, L.; Shi, G.; Maiz, J.; Liu, G.; Wang, D.; Mijangos, C.; Müller, A.J. Effect of Nanoconfinement on the Isodimorphic Crystallization of Poly(butylene succinate-ran-caprolactone) Random Copolymers. Macromolecules 2020, 53, 6486-6497. [CrossRef]

28. Pérez-Camargo, R.A.; Liu, G.; Cavallo, D.; Wang, D.; Müller, A.J. Effect of the crystallization conditions on the exclusion/inclusion balance in biodegradable poly(butylene succinate-ran-butylene adipate) copolymers. Biomacromolecules 2020, 21, $3420-3435$. [CrossRef]

29. Schäfer, M.; Yuan, S.; Petzold, A.; Pérez-Camargo, R.A.; Müller, A.J.; Thurn-Albrecht, T.; Saalwächter, K.; Schmidt-Rohr, K. Asymmetric co-unit inclusion in statistical copolyesters. Macromolecules 2021, 54, 835-845. [CrossRef]

30. Wei, X.W.; Huang, G.; Wang, J.; Meng, X.; Zhou, Q.; Ye, H.M. Tailoring Crystallization of Random Terpolyester: Combination of Isodimorphism and Isomorphism. Macromolecules 2020, 53, 8918-8927. [CrossRef]

31. Zhang, B.; Wei, Z.; Zhao, Y.; Che, R.; Wang, Y.; Leng, X.; Li, Y. Isodimorphic aliphatic copolyester as midblock of poly (l-lactide)based triblock copolymers towards largely enhanced impact toughness. Eur. Polym. J. 2019, 111, 28-37. [CrossRef]

32. Ye, H.M.; Wang, J.; Wang, C.S.; Li, H.F. Unique Isodimorphism of poly (decamethylene succinate-ran-decamethylene fumarate) Large pseudoeutectic region and fantastic crystallization/melting behavior. Macromolecules 2019, 52, 1447-1457. [CrossRef]

33. Zhang, C.; Pérez-Camargo, R.A.; Zheng, L.; Zhao, Y.; Liu, G.; Wang, L.; Wang, D. Crystallization of poly (hexamethylene carbonate)-co-poly (hexamethylene urethane) segmental block copolymers: From single to double crystalline phases. Polymer 2021, 222, 123675. [CrossRef]

34. Zhang, Q.; Song, M.; Xu, Y.; Wang, W.; Wang, Z.; Zhang, L. Bio-based polyesters: Recent progress and future prospects. Prog. Polym. Sci. 2021, 120, 101430. [CrossRef]

35. Yu, Y.; Wei, Z.; Zheng, L.; Jin, C.; Leng, X.; Li, Y. Competition and miscibility of isodimorphism and their effects on band spherulites and mechanical properties of poly (butylene succinate-co-cis-butene succinate) unsaturated aliphatic copolyesters Polymer 2018, 150, 52-63. [CrossRef]

36. Ciulik, C.; Safari, M.; Martinez de Ilarduya, A.; Morales-Huerta, J.C.; Iturrospe, A.; Arbe, A.; Müller, A.J.; Muñoz-Guerra, S. Poly (butylene succinate-ran- $\varepsilon$-caprolactone) copolyesters: Enzymatic synthesis and crystalline isodimorphic character. Eur. Polym. J. 2017, 95, 795-808. [CrossRef]

37. Safari, M.; Martínez de Ilarduya, A.; Mugica, A.; Zubitur, M.; Muñoz-Guerra, S.; Müller, A.J. Tuning the thermal properties and morphology of isodimorphic poly [(butylene succinate)-ran-( $\varepsilon$-caprolactone)] copolyesters by changing composition, molecular weight, and thermal history. Macromolecules 2018, 51, 9589-9601. [CrossRef]

38. Safari, M.; Mugica, A.; Zubitur, M.; Martínez de Ilarduya, A.; Muñoz-Guerra, S.; Müller, A.J. Controlling the isothermal crystallization of isodimorphic PBS-ran-PCL random copolymers by varying composition and supercooling. Polymers 2020, $12,17$. [CrossRef]

39. Cao, A.; Okamura, T.; Ishiguro, C.; Nakayama, K.; Inoue, Y.; Masuda, T. Studies on syntheses and physical characterization of biodegradable aliphatic poly (butylene succinate-co- $\varepsilon$-caprolactone) s. Polymer 2002, 43, 671-679. [CrossRef]

40. Jin, C.; Wei, Z.; Yu, Y.; Sui, M.; Leng, X.; Li, Y. Copolymerization of ethylene brassylate with $\delta$-valerolactone towards isodimorphic random copolyesters with continuously tunable mechanical properties. Eur. Polym. J. 2018, 102, 90-100. [CrossRef]

41. Chartoff, R.P.; Turi, E.A. Thermal Characterization of Polymeric Materials; Academic Press: New York, NY, USA, 1997; Volume 1, p. 513.

42. Hiemenz, P.C.; Lodge, T.P. Polymer Chemistry; CRC Press: Boca Raton, FL, USA, 2007.

43. Fox, T.G. Influence of diluent and of copolymer composition on the glass temperature of a polymer system. Bull. Am. Phys. Soc. 1956, 1, 123.

44. Tsagaropoulos, G.; Eisenberg, A. Dynamic mechanical study of the factors affecting the two glass transition behavior of filled polymers. Similarities and differences with random ionomers. Macromolecules 1995, 28, 6067-6077. [CrossRef] 